\title{
Mechanisms of Neural Synchrony in the Septohippocampal Pathways Underlying Hippocampal Theta Generation
}

\author{
Brian H. Bland, Scott D. Oddie, and Luis V. Colom \\ Department of Psychology, Behavioral Neuroscience Research Group, University of Calgary, Calgary, \\ Alberta, Canada T2N 1N4
}

\begin{abstract}
Using urethane-anesthetized rats, 18 simultaneously recorded septohippocampal cell pairs (36 individual cells), each classified as theta-related according to the criteria of Colom and Bland (1987), were studied during four spontaneously occurring hippocampal field conditions: (1) large amplitude irregular activity (LIA) only; (2) the transition from LIA to theta; (3) theta only; and (4) the transition from theta to LIA. The main objective was to study the temporal relationships and degree of neural synchrony between the discharges of the cell pairs, using both time-averaged and time-dependent joint peristimulus time histogram correlation techniques, during the four conditions, to determine their contribution to the control of oscillation and synchrony (theta) in the hippocampus. The study demonstrated that the transition from the LIA state to the theta field state in the hippocampus required a temporal sequence of changes in
\end{abstract}

theta-related cellular activity occurring on average $500 \mathrm{msec}$ preceding the transition: (1) the medial septum inhibits hippocampal theta-OFF cells; (2) medial septal tonic theta-ON cells provide tonic depolarizing inputs to initiate membrane potential oscillations (MPOs) in hippocampal phasic theta-ON cells, whereas medial septal phasic theta-ON cells synchronize the MPOs of hippocampal phasic theta-ON cells and the discharges of hippocampal tonic theta-ON cells. Much of the time preceding the LIA to theta transition is accounted for by recruitment of these theta-related cell populations. Conversely, "turning off" the theta state occurs abruptly and involves the medial septal disinhibition of hippocampal theta-OFF cells.

Key words: mechanisms; neural synchrony; septohippocampal; theta generation; membrane potentials; joint peristimulus time histograms
Interest in hippocampal formation field activity has reached an unprecedented peak since its first description by Saul and Davis in 1933, as indicated both by the increasing number of studies and very recent reviews published in the area (Dutar et al., 1995; Vinogradova, 1995; Vertes and Kocsis, 1997; Bland and Oddie, 1998). Possible reasons for this interest are the inclusion of hippocampal theta field activity within the more general context of oscillation and synchrony in the CNS (Bland and Colom, 1993) and evidence for its involvement in processes ranging from hippocampal synaptic plasticity (Pavlides et al., 1988; Buzsaki, 1989; Huerta and Lisman, 1993) and various functions such as sensorimotor behavior (Bland, 1986; Oddie and Bland, 1998), registration and retrieval of information from the cortex (Miller, 1991), and the hippocampal processing of spatial information (O'Keefe and Recce, 1993; Skaggs and MacNaughton, 1996).

Limbic cortex represents multiple synchronizing systems. Subsets of cells in these structures exhibit membrane potential oscillations as a result of intrinsic properties of membrane currents. These cells also receive inputs from other cells in the same structure, as well as from cells extrinsic to the structure. A major

\footnotetext{
Received Sept. 23, 1998; revised Dec. 16, 1998; accepted Feb. 2, 1999.

This work was supported by Natural Sciences and Engineering Research Council of Canada Grant A9935 to B.H.B., an Alberta Heritage Foundation for Medical Research postdoctoral fellowship to L.V.C., and an Alberta Heritage Foundation for Medical Research postgraduate fellowship to S.D.O. We are indebted to Prof. Jos Eggermont for his assistance with the JPSTH analyses performed in this paper.

Correspondence should be addressed to Brian H. Bland, Department of Psychology, Behavioral Neuroscience Research Group, The University of Calgary, 2500 University Drive, Northwest Calgary, Alberta, Canada T2N 1 N4.

Dr. Oddie's present address: Department of Psychology, Red Deer College, Box 5005, Red Deer, Alberta, Canada T4N 5H5.

Dr. Colom's present address: Department of Neurology, Baylor College of Medicine, One Baylor Plaza, Houston, TX 77030.

Copyright (C) 1999 Society for Neuroscience $\quad 0270-6474 / 99 / 193223-15 \$ 05.00 / 0$
}

source of extrinsic inputs are the ascending brainstem hippocampal synchronizing pathways originating in the rostral pontine region, ascending and synapsing with midline caudal diencephalic nuclei, which in turn send projections to the medial septal region. The medial septal region is the critical node in the ascending pathways, sending both cholinergic and GABAergic projections to the hippocampus (Vertes and Kocsis, 1997; Bland and Oddie, 1998). An understanding of the functional significance of oscillation and synchrony in limbic cortex will require an understanding of how intrinsic and extrinsic properties interact. Given the critical role of the medial septum in the control of oscillation and synchrony in the hippocampus, septohippocampal cells are ideal candidates for investigating such interactions. Although they have been the subject of numerous investigations, we are aware of only two previous studies in the literature that looked at the relationship between pairs of simultaneously recorded septohippocampal cells (Macadar et al., 1970; Alonso et al., 1987), both studies using time-averaged cross-correlation techniques.

In the present study using urethane-anesthetized rats, 18 simultaneously recorded septohippocampal cell pairs (36 individual cells), each classified as theta-related according to the criteria of Colom and Bland (1987), were studied during four spontaneously occurring hippocampal field conditions: (1) large amplitude irregular activity (LIA) only; (2) the transition from LIA to theta; (3) theta only, and (4) the transition from theta to LIA. The main objective was to study the temporal relationships and degree of neural synchrony between the discharges of the cell pairs during the four conditions, using both time-averaged and timedependent joint peristimulus time histogram (JPSTH) crosscorrelation techniques, to determine their contribution to the control of oscillation and synchrony (theta) in the hippocampus. 
Figure 1. A, A diagrammatic representation of the recording arrangement. A tungsten microelectrode was fixed in the region of the stratum moleculare of the dentate on the right side of the brain to record hippocampal field activity (data not shown). Glass microelectrodes carried in independent micromanipulators were simultaneously lowered into the medial septum/vertical limb of the diagonal band of Broca and the hippocampal formation on the left side of the brain, respectively, for the isolation and recording of single cells. $B$, A diagrammatic reconstruction of cells recorded in the hippocampal formation and classified as theta-related according to the system of Colom and Bland (1987). Seven cells in the CA1 cell body layer (solid circles) and seven cells in the dentate cell body layer (solid circles), for a total of 14 cells, were classified as theta-ON cells (see Results for subclassifications). One cell in the upper blade of the dentate cell body layer was classified as nonrelated (solid square). One cell in the CA1 cell layer (open circle), one cell in the stratum lacunosum region (open circle), and one cell in the upper blade of the dentate cell layer (open circle), for a total of three cells, were classified as theta-OFF cells (see Results for subclassifications). $C$, A diagrammatic reconstruction of the 18 cells recorded in the medial septal nuclei. All cells were classified as theta-ON (solid circles) and were recorded in a depth range (from the dural surface) of 4.7-5.7 $\mathrm{mm}$. Histology was reconstructed using Swanson's (1992) atlas.
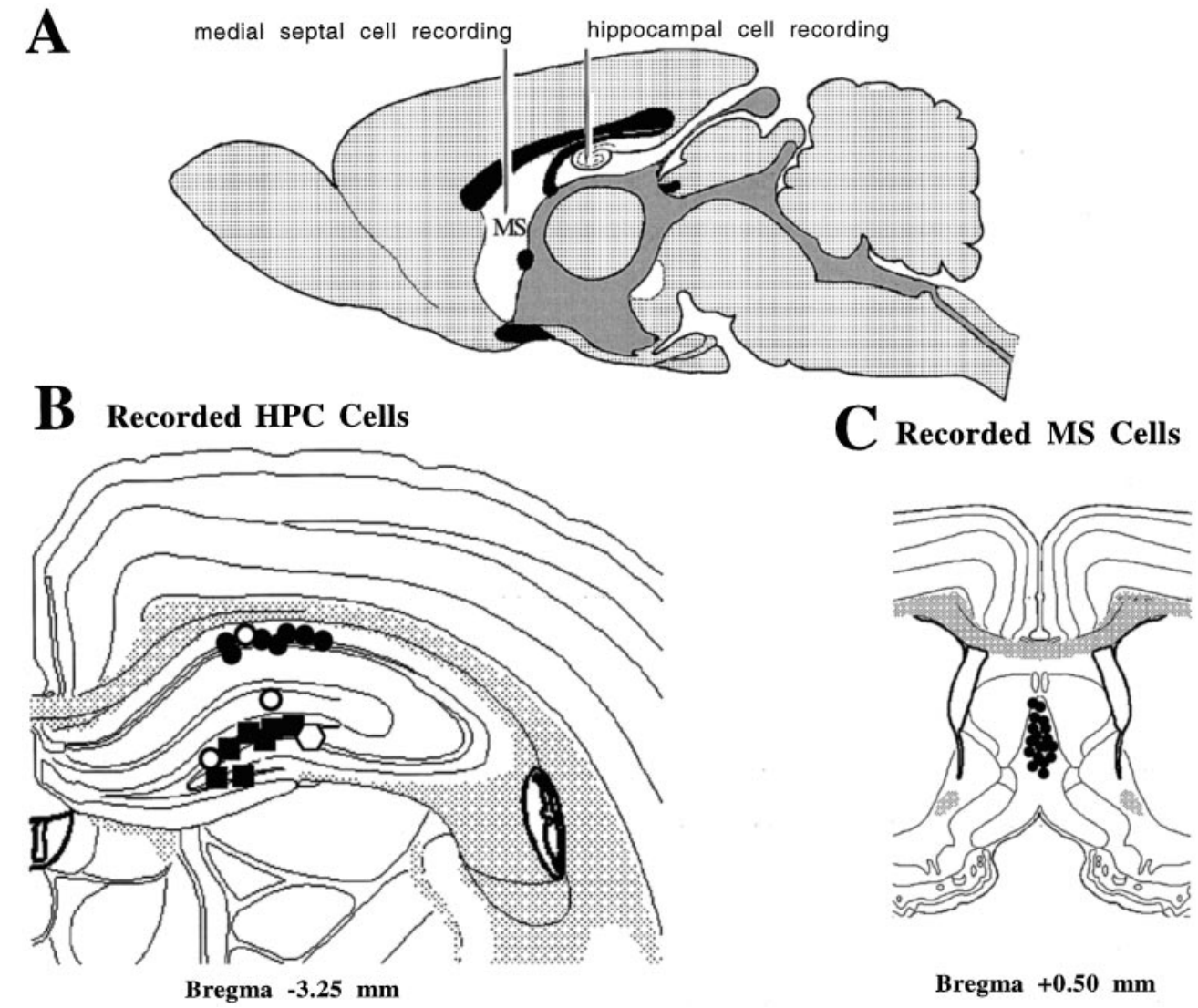

Bregma $+0.50 \mathrm{~mm}$
Portions of these data have appeared in abstract form (Bland et al., 1997).

\section{MATERIALS AND METHODS}

Data were obtained from 18 male Long-Evans rats $(0.25-0.40 \mathrm{~kg})$ supplied by the Life and Environmental Sciences Animal Care Facility at the University of Calgary. The rats were initially anesthetized with a mixture of halothane (M.T.C. Pharmaceuticals) in oxygen (1.5\% minimum alveolar concentration) for jugular cannula insertion. Halothane was then discontinued, and urethane (ethyl carbamate, $0.8 \mathrm{gm} / \mathrm{kg}$ ) was administered via the jugular cannula as required for the remaining surgical and experimental procedures. After insertion of a tracheal cannula, the rat was secured in a stereotaxic apparatus, core temperature was maintained at $37^{\circ} \mathrm{C}$ (Harvard Instruments heating pad), and heart rate was monitored constantly throughout the experiment.

Rats were prepared for stereotaxic surgery in the standard manner. Bregma and lambda were levelled to horizontal, and bregma was used as a reference point for the stereotaxic coordinates. An uninsulated tungsten wire placed in the cortex, anterior to bregma, served as an indifferent electrode, and the stereotaxic frame was connected to ground. A tungsten microelectrode $(0.2-0.5 \mathrm{M} \Omega$ ) for recording hippocampal field activity was placed in the right dorsal hippocampal formation in the dentate molecular layer ( $3.3 \mathrm{~mm}$ posterior to bregma, $2.0 \mathrm{~mm}$ lateral to the midline, and $2.8 \mathrm{~mm}$ ventral to the dural surface). Hippocampal cell recordings were made in the left hippocampus (at the same posterior and lateral coordinates and depths ranging from 1.8 to $4.8 \mathrm{~mm}$ ventral to the dural surface) using glass microelectrodes (5-10 $\mathrm{M} \Omega$ filled with $0.5 \mathrm{~m}$ sodium acetate mixed with $2 \%$ Pontamine sky blue). Medial septal (medial septal nucleus and the nucleus of the vertical limb of the diagonal band of Broca) cell recordings were made $0.5 \mathrm{~mm}$ anterior to bregma, $0.0-0.5 \mathrm{~mm}$ lateral to the midline, and ventral $3.9-6.0 \mathrm{~mm}$ from the dural surface, using glass microelectrodes similar to those used for the hippocampal cell recordings. Hippocampal and septal microelectrodes were carried in independent microdrives. A diagrammatic representation of the recording arrangement is shown in Figure $1 A$. Electrode tip locations were marked by passing $50 \mu \mathrm{A}$ of current for $10 \mathrm{~min}(5 \mathrm{~min}$ cathodal, 5 min anodal). After perfusion and fixation of the brain, frozen sections $(40 \mu \mathrm{m})$ were taken serially, mounted on glass slides, and stained with thionine for subsequent verification of hippocampal field and cellular recording sites and medial septal recording sites.

Brain signals, amplified and displayed in the conventional manner, were stored on FM tape for subsequent off-line analysis. The simultaneously recorded hippocampal and septal cell discharges were recorded during four hippocampal field conditions: (1) during spontaneously occurring LIA only, (2) during the transition from spontaneously occurring LIA to spontaneously occurring theta, (3) during spontaneously occurring theta only, and (4) during the transition from spontaneously occurring theta to spontaneously occurring LIA. Stable cell recordings were made for an average of $30 \mathrm{~min}$ to insure that a minimum of 5-10 transitions were acquired for analysis. Analysis of data segments was accomplished using a PC microcomputer and a software acquisition package (DataWave Technologies, Longmount, CO). Cell activity was digitized through a 12-bit analog-to-digital converter and sampled at a frequency of $1.6 \mathrm{kHz}$. The field activity was simultaneously sampled at a frequency of $133 \mathrm{~Hz}$. Each data segment was subjected to a real time fast Fourier analysis and classified as either theta or LIA by the following criteria: (1) theta was defined as a sinusoidal-like waveform with a peak frequency of $2-8 \mathrm{~Hz}$ and a small bandwidth, and (2) LIA was defined as a large amplitude irregular activity with a broad frequency band (0.525.0 Hz) (Leung et al., 1982).

Analysis of a digitized data segment provided the mean, SEM, and the range of the discharge rate of the cell (in hertz), an autocorrelation (AC) analysis that produced a histogram of the discharge pattern of the cell, and a cross-correlation (X-CORR) analysis that produced a function indicating the strength of any relationship (calculated as a Rho value) between the discharge of the cell versus the HPC field or between the 


\begin{tabular}{|c|c|c|c|c|c|}
\hline \multirow[b]{2}{*}{ Anatomical location } & \multirow[b]{2}{*}{$n$} & \multirow[b]{2}{*}{ Classification } & \multirow[b]{2}{*}{$n$} & \multicolumn{2}{|c|}{ Discharge rate } \\
\hline & & & & HPC theta & HPC LIA \\
\hline \multirow[t]{3}{*}{ HPC-CA1 cell body layer } & 8 & Phasic theta-ON & 3 & $10.5 \pm 0.8$ & $3.6 \pm 0.4$ \\
\hline & & Tonic theta-ON & 4 & $8.5 \pm 0.6$ & $3.9 \pm 0.3$ \\
\hline & & Tonic theta-OFF & 1 & $0.0 \pm 0.0$ & $3.1 \pm 0.4$ \\
\hline HPC-stratum lacunosum & 1 & Phasic theta-OFF & 1 & $0.8 \pm 0.3$ & $8.8 \pm 0.4$ \\
\hline \multirow[t]{4}{*}{ HPC-dentate granule cell layer } & 9 & Phasic theta-ON & 2 & $3.6 \pm 0.6$ & $0.4 \pm 0.1$ \\
\hline & & Tonic theta-ON & 5 & $10.3 \pm 0.5$ & $5.8 \pm 0.6$ \\
\hline & & Tonic theta-OFF & 1 & $0.0 \pm 0.0$ & $4.6 \pm 0.2$ \\
\hline & & Non-related & 1 & $8.4 \pm 0.3$ & $7.5 \pm 0.2$ \\
\hline \multirow[t]{2}{*}{$\mathrm{MS} / \mathrm{vDBB}$} & 18 & Phasic theta-ON & 12 & $21.6 \pm 0.4$ & $14.8 \pm 0.8$ \\
\hline & & Tonic theta-ON & 6 & $17.6 \pm 1.2$ & $13.0 \pm 1.7$ \\
\hline Total & 36 & & 36 & & \\
\hline
\end{tabular}

two cells during the occurrence of hippocampal theta or LIA. For cross-correlation analysis, both the digitized field activity and the spike train were converted to ASCII files and split into 512-bit (3.85 sec) segments. Each spike train segment was convolved with a Gaussian kernel $(\delta=15 \mathrm{msec})$; the resulting spike density function reflected the interburst rather than the intraburst spike intervals (Ahmed and Rao, 1975; Richmond et al., 1987) and cross-correlated relative to the hippocampal field activity using a customized frequency domain algorithm (Press et al., 1986). At least five segments were averaged to produce the final X-CORR.

Based on the above analyses, cells were classified either as thetarelated or non-theta-related according to the criteria that have been used previously in the hippocampal formation (Colom and Bland, 1987). These criteria are based on spike train dynamics of cells in relation to simultaneously recorded hippocampal field states of theta and LIA. Theta-related cells were classified as theta-ON or theta-OFF, with subclassifications as phasic or tonic.

JPSTHs (Gerstein, 1970) (see Fig. 8A, top panel for identification of all the components of a JPSTH) were calculated for three representative theta-ON cell pairs and a cell pair consisting of a tonic medial septal cell and a nonrelated hippocampal cell, during each of the four hippocampal field conditions (analysis of pairs made up of a theta-OFF cell could not be subjected to JPSTH analysis). In all of these conditions, the positive peak of the theta wave was used as the stimulus trigger for the conditions of theta only and the LIA to theta and theta to LIA transition periods. The positive going portion of the LIA was used for the LIA only condition. Three types of joint peristimulus time histograms were calculated: (1) the raw JPSTH, (2) the predicted JPSTH, and (3) the normalized JPSTH. Because the effects of an external stimulus and the effects of neural connectivity on neural synchrony are additive (Perkel et al., 1967), this allows a correction for the effects of the stimulus. That is, treating the theta trigger as a "stimulus" to produce a predicted JPSTH and then subtracting it from the raw JPSTH to produce a normalized JPSTH allowed a determination of any significant synchrony remaining between the respective cell pair combinations. Significant synchrony remaining after such a correction, under the conditions of the present study, was interpreted as being caused by the intrinsic membrane potential oscillations (MPOs). These have been recorded in hippocampal neurons in vitro (Bland et al., 1988; Leung and Yim, 1988, 1991; MacVicar and Tse, 1989; Tse and MacVicar, 1989; Yim and Leung, 1988) and in vivo (Fujita and Sato, 1964; Artemenko, 1973; Fox, 1989; Konopacki et al., 1992; Leung and Yim, 1986; Nunez et al., 1987, 1990a,b,c; Konopacki et al., 1992; Munoz et al., 1990). In each of the calculated JPSTHs, the bin width was $9 \mathrm{msec}$, and the cross-correlation functions were calculated for the duration of $1 \mathrm{sec}$ before the trigger point and $1 \mathrm{sec}$ after trigger. The raw JPSTH shows the dynamic discharge synchrony of the two cells, which is a function of time and varies in response to both spontaneous ("uncontrolled") and stimulus factors (in the present study, theta). The predicted JPSTH is a theoretical one in which the cell discharges in the two spike trains are assumed to be statistically independent, thus the discharge probabilities of the two cells are related only to the stimulus (theta). The normalized JPSTH com- pares the raw and predicted JPSTH matrices to calculate the amount of correlation that is left over between the cells when the stimulus condition (theta) is taken out. The upper and lower limits calculated for the cross-correlograms (CCGs) in the normalized JPSTHs were expressed as Rho values. Based on the sample lengths $(2000 \mathrm{msec})$ and the bin widths (9 msec), the SDs for the CCGs were calculated and used to test the null hypothesis that the upper and lower limits did not differ from the mean. A confidence limit of $95 \%(p \leq 0.05)$ was accepted as the significance level. The time-dependent correlation in each JPSTH is reflected by the diagonal histogram and is termed the coincidence histogram (CIN). The bin width for the CINs was computed from the " 0 " diagonal strip, and the calibration bar is indicated on Figure $8 A$. A regular time-averaged CCG was also calculated for each JPSTH.

\section{RESULTS}

\section{Histology}

The results are presented for a total of 36 cells (18 septohippocampal cell pairs) that were stable throughout the entire time period required to collect data during the four experimental conditions. A diagrammatic reconstruction of 18 cells recorded in the hippocampus is presented in Figure $1 B$. Seven cells in the CA1 cell body layer (solid circles), and seven cells in the dentate cell body layer (solid squares), for a total 14 cells, were classified as theta-ON cells. One cell in the upper blade of the dentate cell body layer was classified as nonrelated (open polygon). Three cells were classified as theta-OFF cells, one in the CA1 layer (open circle), one in the stratum lacunosum (open circle), and one in the upper blade of the dentate cell layer (open square). A diagrammatic reconstruction of the 18 cells recorded in the medial septal nuclei is presented in Figure 1C. All 18 cells located in the medial septal nuclei were classified as theta-ON cells, located close to the midline and in a depth range of $4.7-5.7 \mathrm{~mm}$ from the dural surface.

\section{Detailed classification of individual theta-related cells}

Table 1 summarizes the detailed classification of theta-related cells (ON or OFF, tonic or phasic) in the hippocampus and the medial septum, along with the mean (and SEM) discharge rates during the spontaneous occurrence of hippocampal theta and LIA field activity. Of the 14 cells in the hippocampus classified as theta-ON, seven were subclassified as phasic (rhythmically bursting and phase-locked to the theta waves), and eight were subclassified as tonic (nonbursting and not phase-locked to the theta waves). Of the three cells in the hippocampus classified as theta$\mathrm{OFF}$, one was subclassified as phasic (during the period when 
theta frequency slowed to $<5 \mathrm{~Hz}$ ), and two were subclassified as tonic. One cell in the hippocampus was classified as nonrelated, that is, the cell did not change its discharge rate or pattern during theta or LIA. Of the 18 cells in the medial septum classified as theta-ON cells, 14 were subclassified as phasic, and four were subclassified as tonic.

\section{Analysis of septohippocampal cell pairs: fast Fourier transforms, autocorrelations, and time-averaged cross-correlations}

The breakdown of the septohippocampal cell combinations was as follows. Medial septal theta-ON/hippocampal theta-ON cell pairs: (1) medial septal phasic theta-ON/hippocampal phasic theta-ON $(n=5)$; $(2)$ medial septal phasic theta-ON/hippocampal tonic theta-ON $(n=5)$; and (3) medial septal tonic theta-ON/ hippocampal tonic theta-ON $(n=4)$. Medial septal theta-ON/ hippocampal theta-OFF cell pairs: (4) medial septal phasic thetaON/hippocampal tonic theta-OFF $(n=2)$; and (5) medial septal tonic theta-ON/hippocampal phasic theta-OFF $(n=1)$. Medial septal theta-ON/hippocampal nonrelated cell pair: (6) medial septal tonic theta-ON/hippocampal nonrelated $(n=1)$. For the purpose of representation, the detailed analysis of one pair of each of the three medial septal theta-ON/hippocampal theta-ON cell combinations and one pair of the three medial septal thetaON/hippocampal theta-OFF cell combinations is presented below.

\section{Representative medial septal phasic theta-ON/hippocampal phasic theta-ON cell pair}

Figure 2 shows the hippocampal field-related discharges of simultaneously recorded cell pair MH5 (a medial septal phasic theta-ON cell/hippocampal phasic theta-ON cell pair). During LIA only, both the cells discharged in an irregular nonbursting pattern (top left panel). During the transition from LIA to theta field activity, the medial septal phasic theta-ON cell discharges changed to a rhythmic bursting pattern that preceded hippocampal theta field activity by $565.0 \mathrm{msec}$ (group data for all 12 medial septal cells: mean, $570.0 \mathrm{msec}$; range, 464.0-893.0 msec). The hippocampal phasic theta-ON cell discharges also changed to a rhythmic bursting pattern but did so coincidently with hippocampal theta field activity (top right panel). During theta only, both cells continued to discharge in a rhythmically bursting pattern, each phase-locked to the extracellularly recorded theta waves (bottom left panel). During the transition from theta to LIA field activity, both the cells ceased discharging in a rhythmically bursting pattern coincident with the rising positivity of the last theta wave (bottom right panel).

The analyses of the hippocampal field and cellular activity of cell pair MH5, during the conditions of theta only and LIA only, are presented in Figure 3. During theta field activity (Fig. $3 A$ ) fast Fourier transform (FFT) analysis produced an averaged frequency spectrum with a peak frequency of $3.6 \mathrm{~Hz}$ and a second harmonic peak at double this value (top left panel). AC analysis of the septal cell $(\mathrm{S})$ produced a histogram with regularly occurring peaks, indicating the cell discharged in rhythmic bursts during theta field activity (top middle panel). The AC histogram resulting from the analysis of the hippocampal cell $(\mathrm{H})$ also indicated a rhythmically bursting discharge pattern (top right panel). Crosscorrelation analysis between the septal cell and the theta field activity produced an X-CORR function indicating a high correlation between the discharge of the cell at a phase of $294^{\circ}$ of the theta wave (bottom left panel). Cross-correlation analysis of the hippocampal cell revealed a strong correlation of the cell dis-
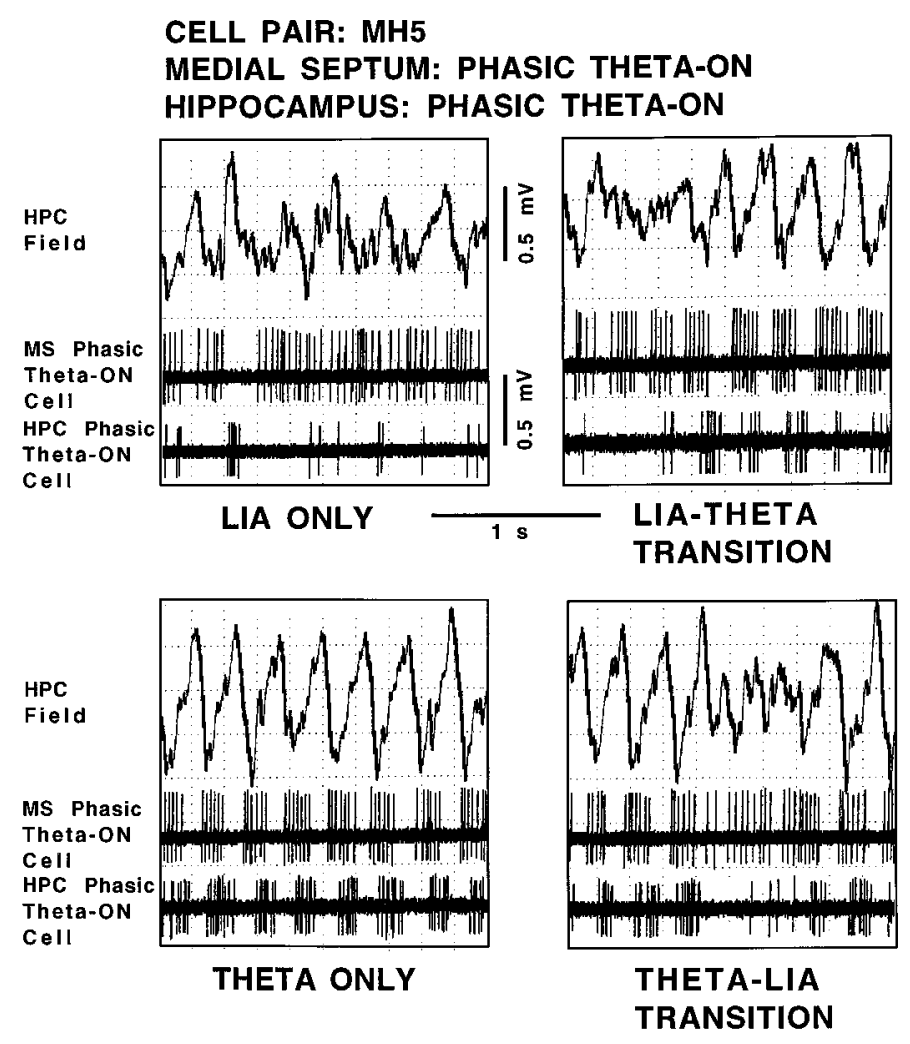

Figure 2. Hippocampal field-related discharges of cell pair MH5, a medial septal phasic theta-ON cell and a hippocampal phasic theta-ON cell. The top trace in each panel is the hippocampal field recorded from the region of the stratum moleculare of the dentate gyrus, and the middle and bottom panels are recordings of the medial septal cell and hippocampal cell, respectively, all simultaneously recorded during the four spontaneously occurring field states: LIA ONLY, LIA-THETA TRANSITION, THETA ONLY, and THETA-LIA TRANSITION.

charge at a phase of $130^{\circ}$ of the theta wave (bottom middle panel). Cross-correlation analysis between the septal cell and the hippocampal cell revealed a strong correlation with a phase of $127^{\circ}$ (bottom right panel). During LIA (Fig. 3B) FFT analysis produced an averaged frequency spectrum with no peak frequency (top left panel). AC analysis of $\mathrm{S}$ produced a flat histogram indicating a nonrhythmic discharge pattern (top middle panel). The AC histogram resulting from the analysis of $\mathrm{H}$ also indicated a nonrhythmic discharge pattern (top right panel). Crosscorrelation analysis revealed no correlations occurring between the septal cell and the hippocampal LIA (bottom left panel), the hippocampal cell and the LIA (bottom middle panel), or between the septal cell and the hippocampal cell (bottom right panel). For the remaining cell pairs, analyses are shown for the theta condition only, because as in cell pair MH5, there were no crosscorrelations occurring during LIA.

\section{Representative medial septal phasic theta-ON/hippocampal tonic theta-ON cell pair}

Figure 4 shows the hippocampal field-related discharges of simultaneously recorded cell pair MH16 (a medial septal phasic theta-ON cell/hippocampal tonic theta-ON cell pair). During LIA only, both the cells discharged in an irregular nonbursting pattern (top left panel). During the transition from LIA to theta field activity, the medial septal phasic theta-ON cell discharges changed to a rhythmically bursting pattern that preceded hippocampal theta field activity by $643.0 \mathrm{msec}$. The hippocampal 
A. cell pair: MH5- THETA
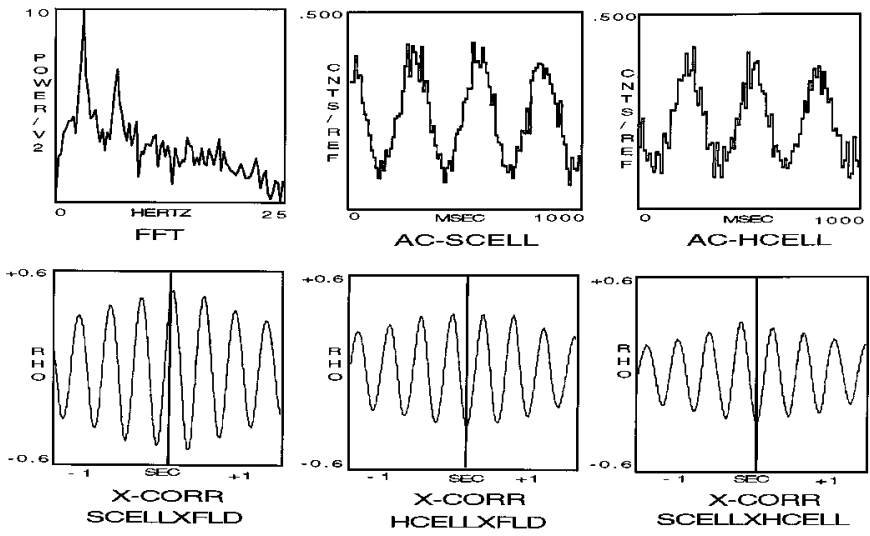

B. CELL PAIR: MHS- LIA
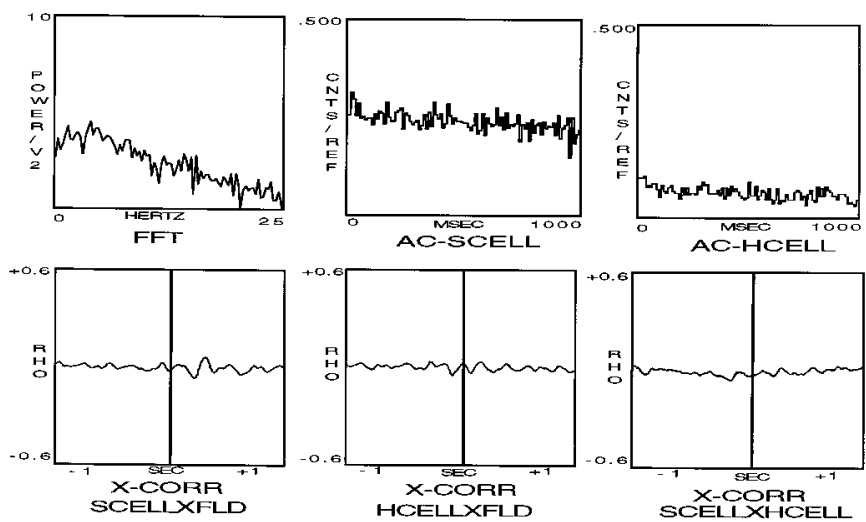

Figure 3. Analyses of the hippocampal field and cellular activity of cell pair MH5. A, During theta field activity. The top left panel is the frequency spectrum resulting from the FFT analysis of the hippocampal theta field activity, the top middle panel is an $\mathrm{AC}$ analysis of $\mathrm{S}$, and the top right panel is an AC histogram of $\mathrm{H}$. The bottom left panel is a crosscorrelation analysis between the septal cell and the theta field activity, the bottom middle panel is a cross-correlation analysis of the hippocampal cell and the theta field activity, and the bottom right panel is a cross-correlation analysis between the septal cell and the hippocampal cell during theta field activity. $B$, The equivalent analyses as in $A$, only made during LIA field activity.

tonic theta-ON cell increased discharge rate coincident with the beginning of theta field activity (top right panel). During theta only, the phasic medial septal theta-ON cell continued to discharge in a rhythmically bursting pattern, phase-locked to the extracellularly recorded theta waves. The hippocampal tonic theta-ON cell continued the increased level of irregular nonbursting discharges (bottom left panel). During the transition from theta to LIA field activity, the medial septal phasic theta-ON cell ceased discharging in a rhythmically bursting pattern nearly coincident with the rising positivity of the last theta wave, and the hippocampal tonic theta-ON cell reduced its irregular, nonbursting discharge rate at the same time (bottom right panel).

\section{Representative medial septal tonic}

\section{theta-ON/hippocampal tonic theta-ON cell pair}

Figure 5 shows the hippocampal field-related discharges of simultaneously recorded cell pair MH8 (a medial septal tonic thetaON/hippocampal tonic theta-ON cell pair). During LIA only, both the cells discharged in an irregular nonbursting pattern (top
CELL PAIR: MH16

MEDIAL SEPTUM : PHASIC THETA-ON HIPPOCAMPUS: TONIC THETA -ON

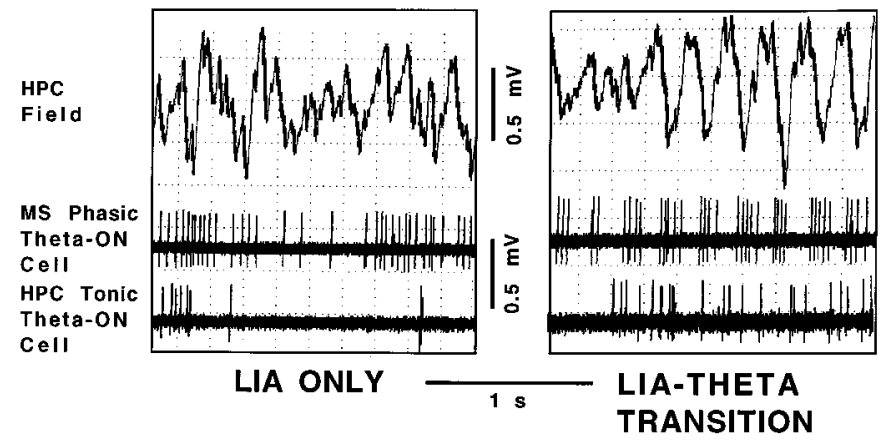

HPC

Field

MS Phasic

Theta-ON

CeII

HPC Tonic

Theta-ON

cell

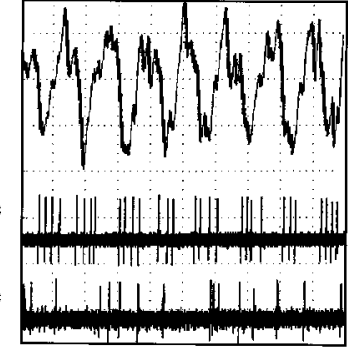

THETA ONLY

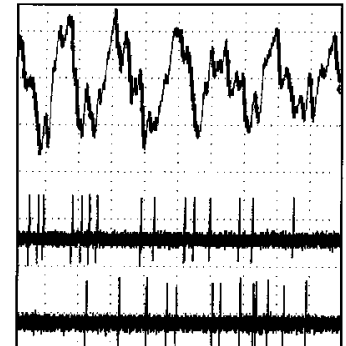

THETA-LIA TRANSITION
Figure 4. Hippocampal field-related discharges of cell pair MH16, a medial septal phasic theta-ON cell and a hippocampal tonic theta-ON cell. The top trace in each panel is the hippocampal field recorded from the region of the stratum moleculare of the dentate gyrus, and the middle and bottom panels are recordings of the medial septal cell and hippocampal cell, respectively, all simultaneously recorded during the four spontaneously occurring field states: LIA ONLY, LIA-THETA TRANSITION, THETA ONLY, and THETA-LIA TRANSITION.

left panel). During the transition from LIA to theta field activity, the medial septal tonic theta-ON cell increased discharge rate coincident with the onset of hippocampal theta field activity (top right panel) (three medial septal tonic theta-ON cells were observed to increase discharge rates before theta onset; group data for these cells: mean, $400.0 \mathrm{msec}$; range, 348.0-469.0 msec; the remaining three medial septal tonic theta-ON cells increased discharge rates coincident with the beginning of theta field activity). During the transition from LIA to theta field activity, the hippocampal tonic theta-ON cell also increased discharge rate coincident with the onset of hippocampal theta field activity (top right panel). During theta only, the medial septal tonic theta-ON cell and the hippocampal tonic theta-ON cell both continued the increased level of irregular nonbursting discharges (bottom left panel). During the transition from theta to LIA field activity, both the medial septal tonic theta-ON cell and the hippocampal tonic theta-ON cell decreased irregular, nonbursting discharge rates coincident with the rising positivity of the last theta wave (bottom right panel).

The analyses of the hippocampal field and cellular activity of cell pair MH16, during the condition of theta only, are presented in Figure $6 A$. During theta field activity, FFT analysis of the hippocampal theta field activity produced an averaged frequency spectrum with a peak frequency of $3.4 \mathrm{~Hz}$ and a second harmonic peak at double this value (top left panel). AC analysis of $\mathrm{S}$ produced a histogram with regularly occurring peaks, indicating 
CELL PAIR: MH8

MEDIAL SEPTUM: TONIC THETA-ON HIPPOCAMPUS: TONIC THETA-ON
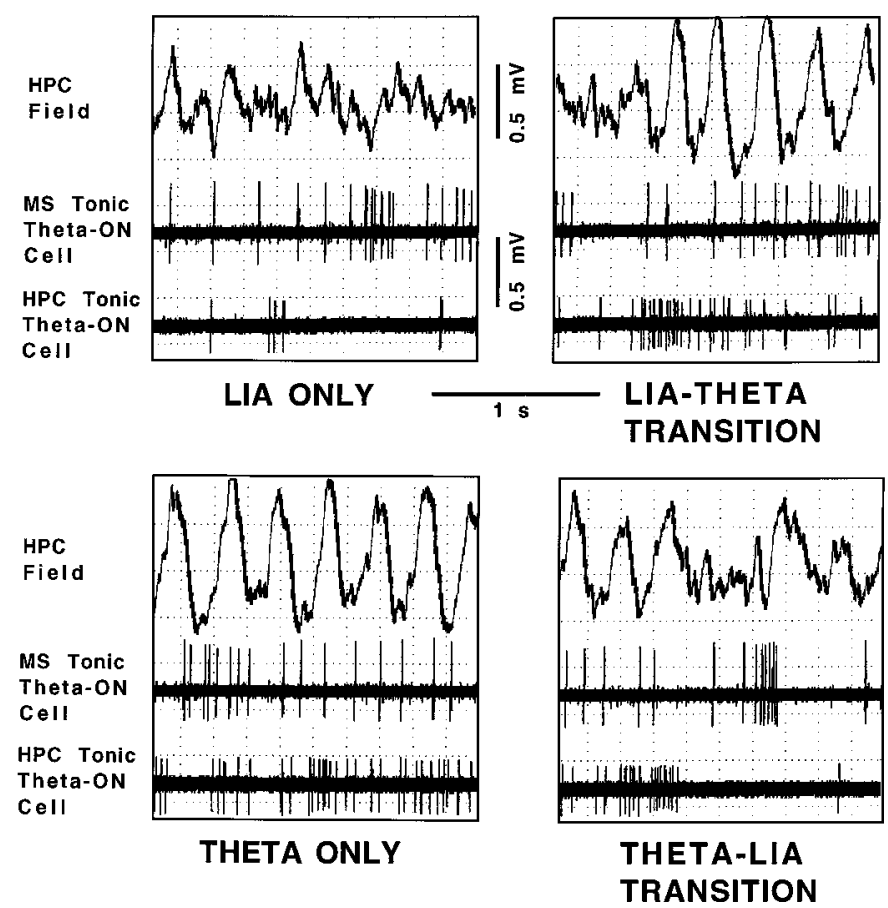

Figure 5. Hippocampal field-related discharges of cell pair MH8, a medial septal tonic theta-ON cell and a hippocampal tonic theta-ON cell. The top trace in each panel is the hippocampal field recorded from the region of the stratum moleculare of the dentate gyrus, and the middle and bottom panels are recordings of the medial septal cell and hippocampal cell, respectively, all simultaneously recorded during the four spontaneously occurring field states: LIA ONLY, LIA-THETA TRANSITION, THETA ONLY, and THETA-LIA TRANSITION.

the cell discharged in rhythmic bursts during theta field activity (top middle panel). The AC histogram resulting from the analysis of $\mathrm{H}$ produced a flat histogram indicating a nonrhythmic discharge pattern (top right panel). Cross-correlation analysis between the septal cell and the theta field activity produced an $\mathrm{X}-\mathrm{CORR}$ function indicating a high correlation between the discharge of the cell at a phase of $294^{\circ}$ of the theta wave (bottom left panel). Cross-correlation analysis of the hippocampal cell indicated a weak correlation between the cell discharge and the theta wave (bottom middle panel), and the same analysis between the septal cell and the hippocampal cell revealed a slightly stronger correlation between the two cells (bottom right panel).

The analyses of the hippocampal field and cellular activity of cell pair MH8, during the condition of theta only, are presented in Figure $6 B$. During theta field activity, FFT analysis of the hippocampal theta field activity produced an averaged frequency spectrum with a peak frequency of $3.6 \mathrm{~Hz}$ (top left panel). AC analysis of S produced a flat histogram during theta field activity, indicating a nonrhythmic discharge pattern (top middle panel). The AC histogram resulting from the analysis of $\mathrm{H}$ also produced a flat histogram, indicating a nonrhythmic discharge pattern (top right panel). Cross-correlation analysis of the septal cell indicated a very weak correlation between the cell discharge and the theta wave (bottom left panel). Cross-correlation analysis of the hippocampal cell indicated there was a moderate correlation between the cell discharge and the theta wave at a phase of $120^{\circ}$ of
A. cELL PAIR: MH16 - THETA
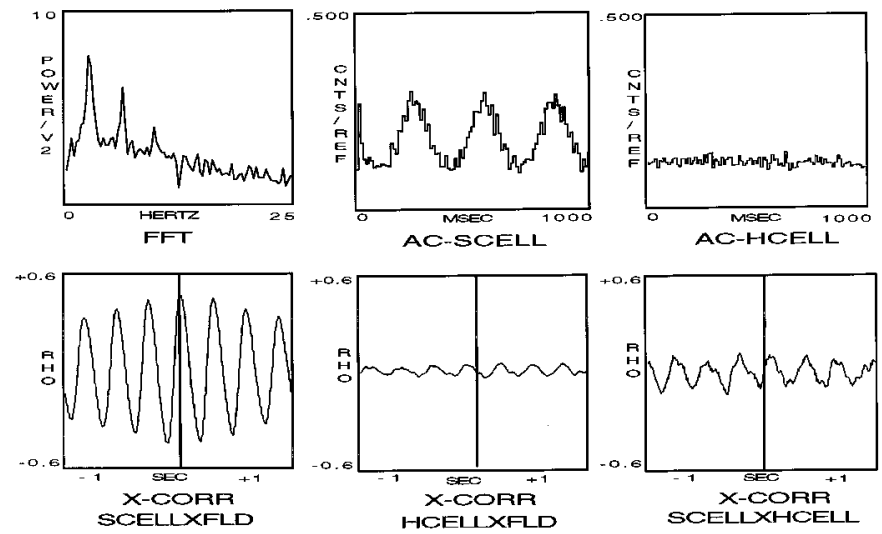

B. CELL PAIR: MHB- THETA
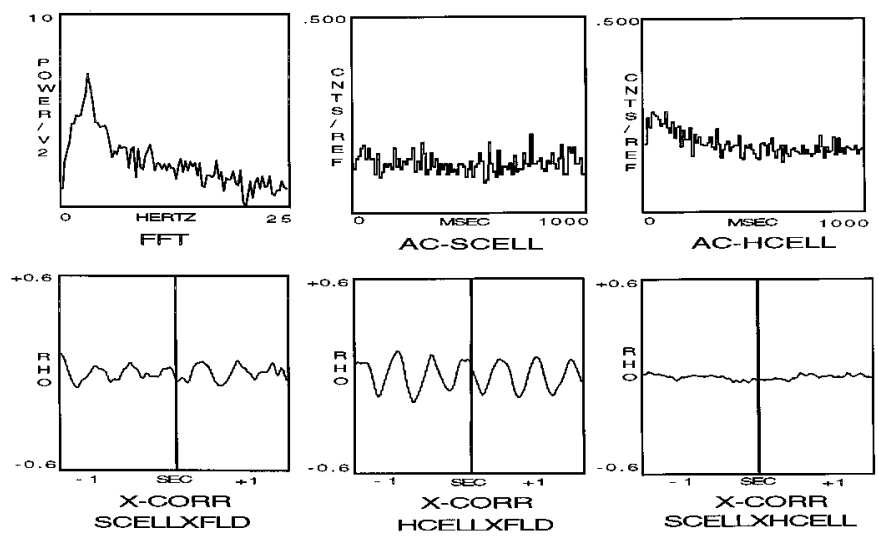

Figure 6. Analyses of the hippocampal field and cellular activity of cell pair MH16 $(A)$ and cell pair MH8 $(B)$ during theta field activity. The top left panel is the frequency spectrum resulting from the FFT analysis analysis of the hippocampal theta field activity, the top middle panel is an $\mathrm{AC}$ analysis of $\mathrm{S}$, and the top right panel is an $\mathrm{AC}$ histogram of $\mathrm{H}$. The bottom left panel is a cross-correlation analysis between the septal cell and the theta field activity, the bottom middle panel is a cross-correlation analysis of the hippocampal cell and the theta field activity, and the bottom right panel is a cross-correlation analysis between the septal cell and the hippocampal cell during theta field activity.

the theta wave (bottom middle panel). Cross-correlation analysis between the septal cell and the hippocampal cell indicated the two were not correlated (bottom right panel).

\section{Representative medial septal phasic theta-ON/hippocampal tonic theta-OFF cell pair}

Figure 7 shows the hippocampal field-related discharges of simultaneously recorded cell pair MH1 (a medial septal phasic thetaON/hippocampal tonic theta-OFF cell pair). During LIA only the septal cell discharged in an irregular nonbursting pattern, and the hippocampal cell discharged in a regular nonbursting pattern (top left panel). During the transition from LIA to theta field activity, the medial septal phasic theta-ON cell discharges changed to a rhythmically bursting pattern that preceded hippocampal theta field activity by $500.0 \mathrm{msec}$ (top right panel). The hippocampal tonic theta-OFF cell ceased discharging $600 \mathrm{msec}$ before the beginning of theta field activity (group data for two tonic hippocampal theta-OFF cells and one phasic hippocampal theta-OFF cell: mean, $503 \mathrm{msec}$ ). During theta only, the medial 
CELL PAIR: MH1

MEDIAL SEPTUM: PHASIC THETA-ON HIPPOCAMPUS: TONIC THETA-OFF
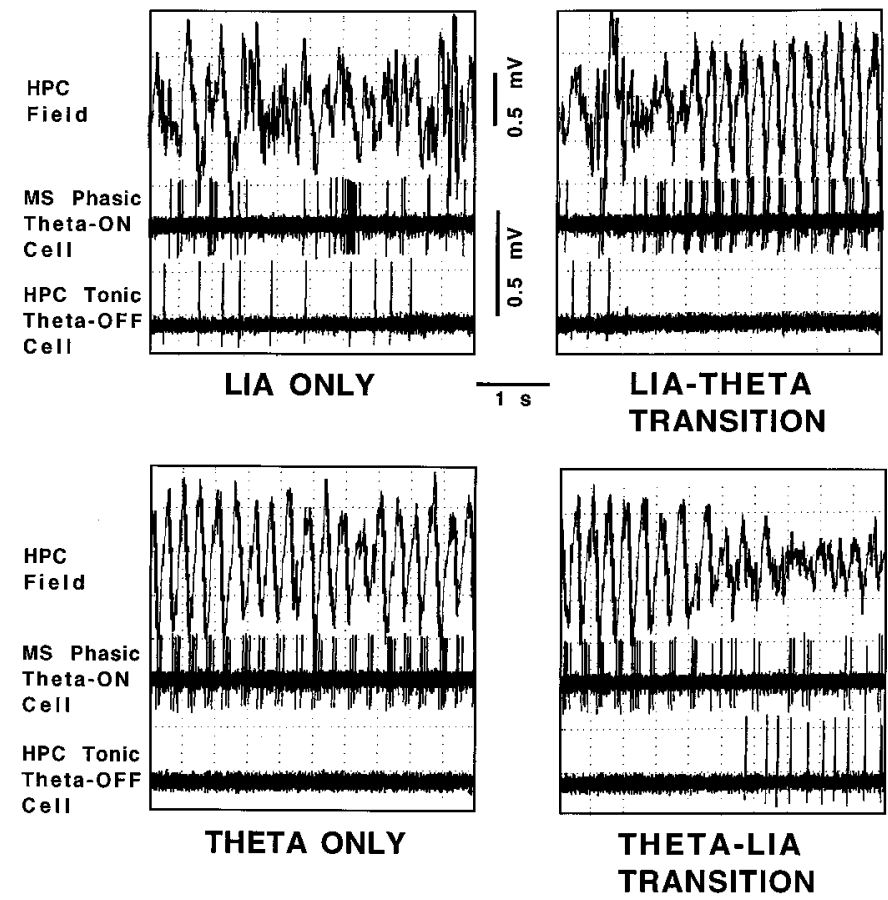

Figure 7. Hippocampal field-related discharges of cell pair MH1, a medial septal phasic theta-ON cell and a hippocampal tonic theta-OFF cell. The top trace in each panel is the hippocampal field recorded from the region of the stratum moleculare of the dentate gyrus, and the middle and bottom panels are recordings of the medial septal cell and hippocampal cell, respectively, all simultaneously recorded during the four spontaneously occurring field states: LIA ONLY, LIA-THETA TRANSITION, THETA ONLY, and THETA-LIA TRANSITION.

septal phasic theta-ON cell continued to discharge in a rhythmically bursting pattern, phase-locked to the extracellularly recorded theta waves. The hippocampal tonic theta-OFF cell failed to discharge when theta field activity was present (bottom left panel). During the transition from theta to LIA field activity, the medial septal phasic theta-ON cell ceased discharging in a rhythmically bursting pattern nearly coincident with the rising positivity of the last theta wave, and the hippocampal tonic theta-OFF cell began a regular, nonbursting discharge pattern coincident with the end of the theta field activity (bottom right panel).

\section{Analysis of septohippocampal cell pairs: JPSTHs}

Detailed JPSTH analyses were performed on all pairs of each of four of the six septohippocampal cell combinations described above. JPSTH analyses could not be performed on cell pairs that included a theta-OFF cell, because by definition these cells did not discharge at significant rates during theta field activity. The JPSTH analysis performed on cell pair MH4 (medial septal tonic theta-ON cell/hippocampal nonrelated cell) did not reveal any significant correlations, and therefore is not shown. Shown below are the JPSTH analyses of a representative cell pair for each of the three septohippocampal combinations.

\section{JPSTH analyses of cell pair MH5 (medial septal phasic theta-ON/hippocampal phasic theta-ON)}

The analysis for the condition of LIA only is shown in Figure $8 \mathrm{~A}$. The PSTs in Figure $8 A$ (top) indicate that both cells discharged in an irregular nonbursting discharge pattern during LIA. The JPSTH matrix and CIN histogram also clearly show that the cell discharges were not synchronized during LIA, and the CCG histogram indicates the cell discharges were not correlated. Figure $8 A$ (middle) shows the same results as illustrated with the raw JPSTH analysis, in this case demonstrating that using LIA as a stimulus fails to contribute to synchrony. The JPSTH matrix in Figure $8 A$ (bottom) demonstrates after correcting for the stimulus (LIA) effects, the cell discharges remained nonrelated. After normalization the CIN was noisy, and the CCG display indicates that the cells were not correlated.

The analysis for the condition of LIA to theta transition is shown in Figure $8 B$. The PSTHs in Figure $8 B($ top $)$ indicate that the medial septal cell became rhythmic during LIA, before the onset of theta, whereas the hippocampal cell became rhythmic at theta onset. The CCG histogram shows the discharges of the cells were rhythmically correlated. The JPSTH matrix and CIN histogram clearly indicate that the cells synchronized their discharges during LIA, before the onset of theta. Figure $8 B$ (middle) shows the same results as illustrated with the raw JPSTH analysis, in this case caused by the synchronizing effects of the stimulus (theta). The JPSTH matrix in Figure $8 B$ (bottom) demonstrates after correcting for the stimulus (theta)-driven synchronizing effects, the cell discharges were strongly related before theta onset. After normalization the CIN was noisy, but the CCG display indicates that the cells were correlated with $3.8 \%$ of the synchrony remaining (group mean, 4.0\%).

The analysis for the condition of theta only is shown in Figure $8 C$. The PSTHs in Figure $8 C$ (top) indicate that both cells were rhythmic during theta, and the CCG histogram shows that the cell discharges were well correlated. The JPSTH matrix and CIN histogram also clearly indicate that the cell discharges were well synchronized during theta. Figure $8 C$ (middle) shows the same results as illustrated with the raw JPSTH analysis, in this case caused by the synchronizing effects of the stimulus (theta). The JPSTH matrix in Figure $8 C$ (bottom) demonstrates after correcting for the stimulus (theta)-driven synchronizing effects, the cell discharges were still strongly related. After normalization the CIN was noisy, but the CCG indicates that the cells were correlated, accounting for $4.4 \%$ of the synchrony (group mean, $4.5 \%$ ).

The analysis for the condition of theta to LIA transition is shown in Figure $8 D$. The PSTHs in Figure $8 D$ (top) indicate that during the transition from theta to LIA field activity both cells ceased discharging in a rhythmically bursting pattern coincident with the last theta wave, and the CCG histogram shows the cells discharges were well correlated. The JPSTH matrix and CIN histogram also clearly indicate that the cell discharges became nonsynchronized abruptly at the theta to LIA transition. Figure $8 D$ (middle) shows the same results as illustrated with the raw JPSTH analysis, in this case caused by the synchronizing effects of the stimulus (theta). The JPSTH matrix in Figure 8D (bottom) demonstrates after correcting for the stimulus (theta)-driven synchronizing effects, the cell discharges were still strongly related during theta field activity. After normalization the CIN was noisy, but the CCG display indicates that the cells were correlated, accounting for $3.2 \%$ of the synchrony (group mean, 3.0\%)

\section{JPSTH analyses of cell pair MH16 (medial septal phasic theta-ON/hippocampal tonic theta-ON)}

The analysis for the condition of LIA only is shown in Figure $9 A$. The PSTHs in Figure $9 A$ (top) indicate that both cells discharged in an irregular nonbursting discharge pattern during LIA, 
A CELL PAIR MH5 - LIA ONLY

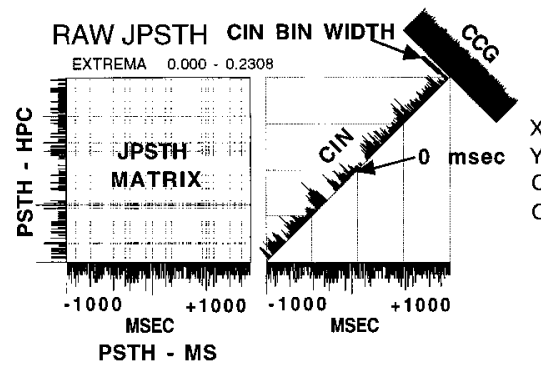

$X-M S$ CELL

CCG: $0.000-0.0189$

$\mathrm{CIN}: \quad 0.000-0.0769$

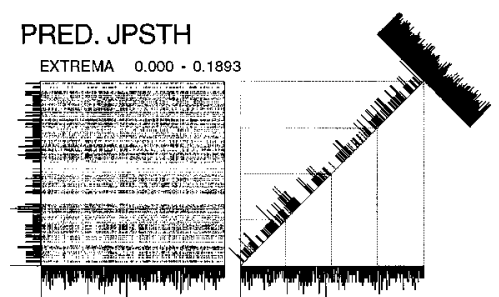

$X-M S C E L L$

$Y$-HPC CELL

CCG: $0.000-0.0161$

CIN: $\quad 0.000-0.0592$

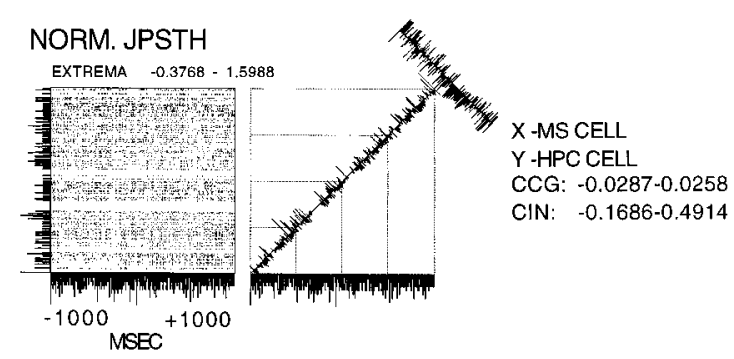

C CELL PAIR MH5 - THETA ONLY
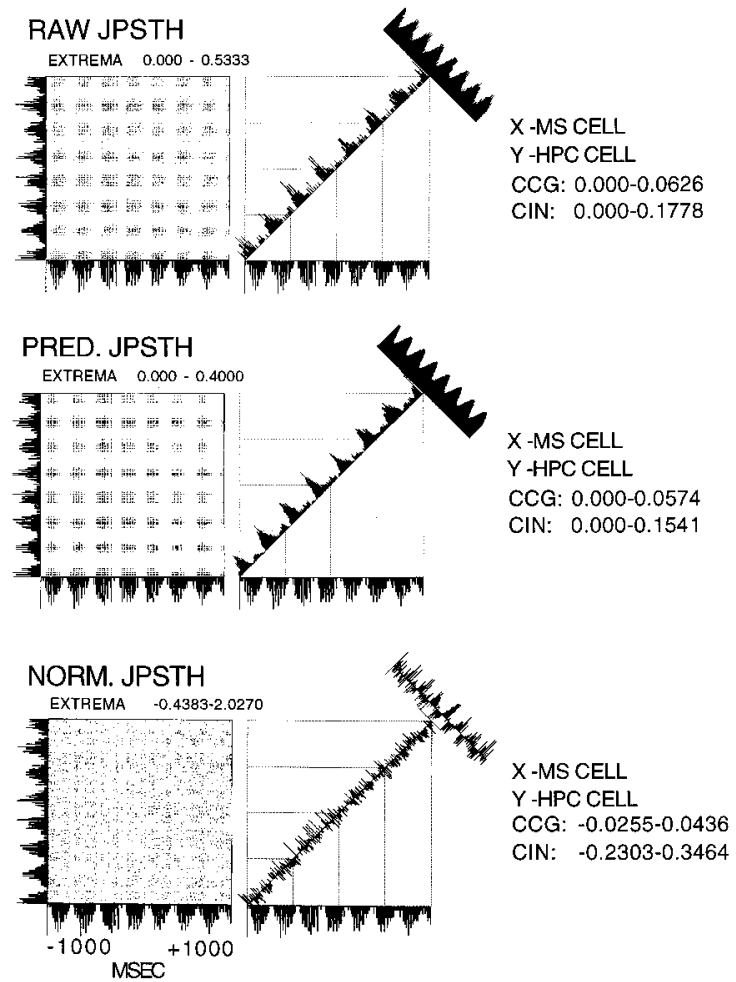

\section{B CELL PAIR MH5 - LIA-THETA TRANSITION}
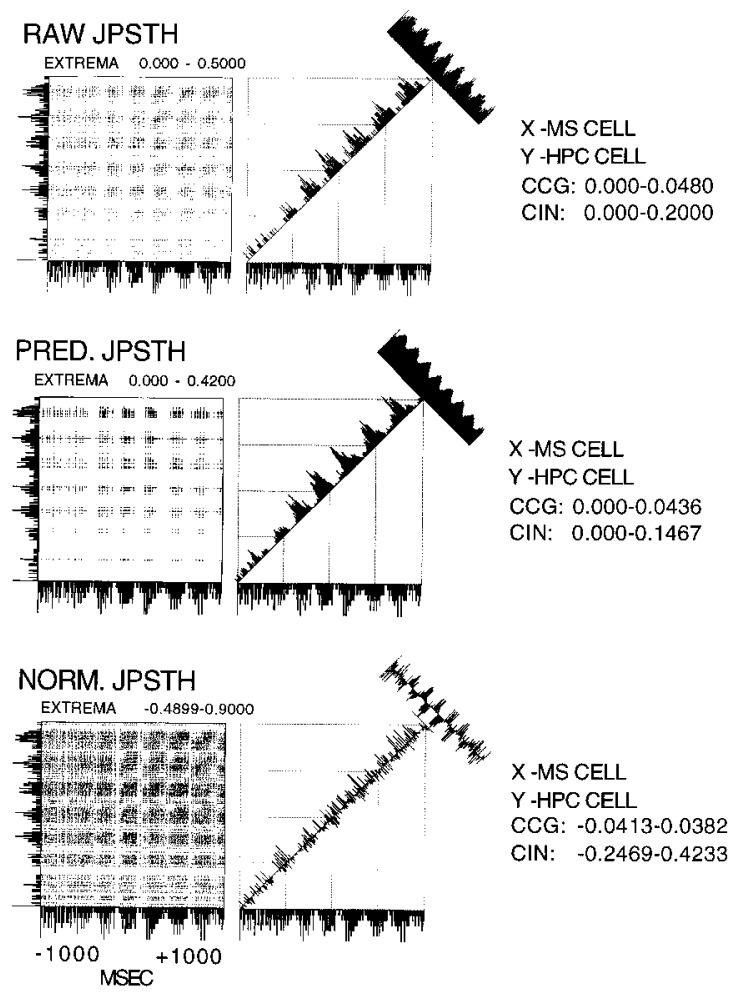

D CELL PAIR MH5 - THETA-LIA TRANSITION
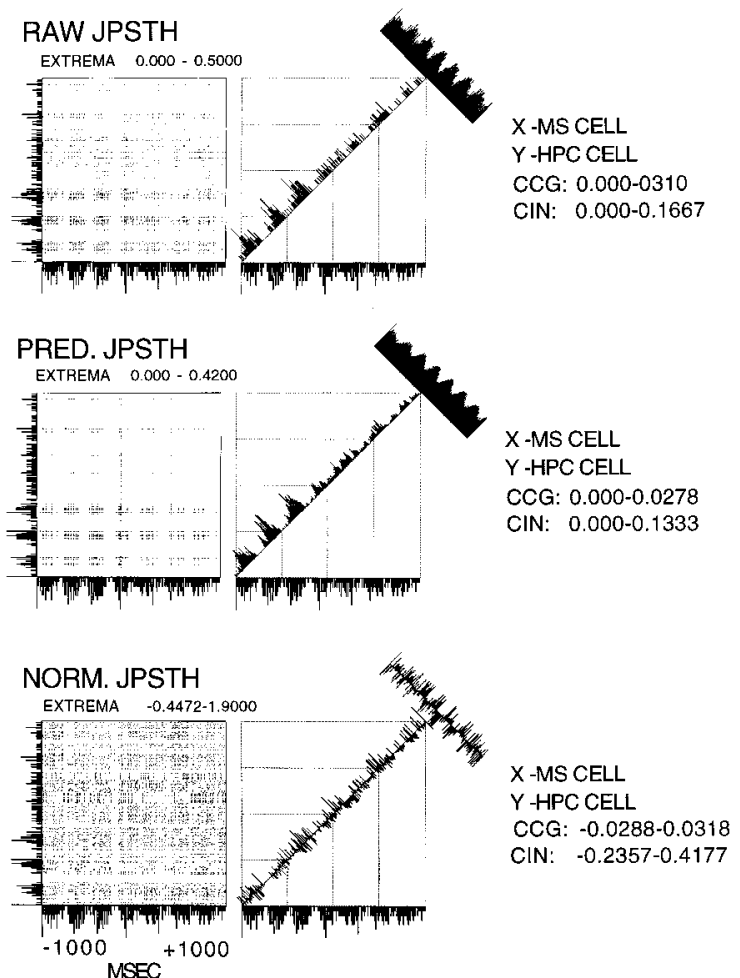

Figure 8. A, JPSTH analysis of cell pair MH5 for the condition of LIA only. For all JPSTHs, the $y$-axis PSTH is the hippocampal cell, and the $x$-axis PSTH is the medial septal cell. The $x$ - and $y$-axis range was -1000 to $+1000 \mathrm{msec}$. Bin width for the PSTHs and the JPSTH matrix was 9 msec, and the display for both these as well as the CCG and CIN histograms was normalized counts per trial (in hertz). The JPSTH matrix and the CCG and CIN histograms for the raw (top), predicted (middle), and normalized (bottom) all indicate a lack of relationship between the cells during LIA only. $B$, JPSTH analysis of cell pair MH5 for the condition of LIA to theta transition. For all JPSTHs, the $y$-axis PST is the hippocampal (Figure legend continues) 
whereas the CCG histogram indicates the cell discharges were not correlated. The JPSTH matrix and CIN histogram also clearly indicate that the cell discharges were not synchronized during LIA. Figure $9 A$ (middle) shows the same results as illustrated with the raw JPSTH analysis, in this case demonstrating that using LIA as a stimulus fails to contribute to synchrony. The JPSTH matrix in Figure $9 A$ (bottom) demonstrates after correcting for the stimulus (LIA) effects, the cell discharges remained nonrelated. After normalization the CIN was noisy, and the CCG display indicates that the cells were not correlated.

The analysis for the condition of LIA to theta transition is shown in Figure 9B. The PSTHs in Figure $9 B($ top $)$ indicate that the medial septal cell became rhythmic during LIA, before the onset of theta, whereas the hippocampal cell remained discharging in an irregular nonbursting pattern. The CCG histogram shows the discharges of the cells were weakly correlated. The JPSTH matrix and CIN histogram clearly indicate that the cells synchronized their discharges during LIA, before the onset of theta. Figure $9 B$ (middle) shows the same results as illustrated with the raw JPSTH analysis, in this case caused by the synchronizing effects of the stimulus (theta). The JPSTH matrix in Figure $9 B$ (bottom) demonstrates after correcting for the stimulus (theta)-driven synchronizing effects, the cell discharges were related before theta onset. After normalization the CIN was noisy, but the CCG display indicates that the cells were very weakly correlated, accounting for $1.8 \%$ of the synchrony (group mean, $1.5 \%)$.

The analysis for the condition of theta only is shown in Figure 9C. The PSTHs in Figure 9C (top) show that the medial septal cell was rhythmically bursting during theta, whereas the hippocampal cell continued discharging in an irregular nonbursting pattern. The CCG histogram shows the cell discharges were weakly correlated, whereas the JPSTH matrix and CIN histogram indicate clearly that the cells synchronized their discharges during theta. Figure $9 C$ (middle) shows the same results as illustrated with the raw JPSTH analysis, in this case caused by the synchronizing effects of the stimulus (theta). The JPSTH matrix in Figure $9 C$ (bottom) demonstrates after correcting for the stimulus (theta)-driven synchronizing effects, the cell discharges were still related. After normalization the CIN was noisy, but the CCG indicates that the cells were very weakly correlated, accounting for $1.5 \%$ of the synchrony (group mean, $1.3 \%$ ).

The analysis for the condition of theta to LIA transition is shown in Figure 9D. The PSTHs in Figure 9D (top) indicate that during the transition from theta to LIA field activity, the medial septal cell ceased discharging in a rhythmically bursting pattern coincident with the last theta wave, whereas the hippocampal cell continued to discharge in an irregular nonbursting pattern. The CCG histogram indicates that the cell discharges were weakly correlated. The JPSTH matrix and CIN histogram also show that the cell discharges became nonsynchronized abruptly at the theta to LIA transition. Figure 9D (middle) shows the same results as illustrated with the raw JPSTH analysis, in this case caused by the synchronizing effects of the stimulus (theta). The JPSTH matrix in Figure 9D (bottom) demonstrates after correcting for the stimulus (theta)-driven synchronizing effects, the cell discharges were not related during theta field activity. After normalization the CIN was noisy, and the CCG display indicates that the cells were not correlated.

\section{JPSTH analyses of cell pair MH8 (medial septal tonic theta-ON/hippocampal tonic theta-ON)}

The analysis for the condition of LIA only is shown in Figure $10 A$. The PSTHs in Figure $10 A$ (top) indicate that both cells discharged in an irregular nonbursting discharge pattern during LIA. The CCG histogram indicates the cell discharges were not correlated, and the JPSTH matrix and CIN histogram clearly show that the cell discharges were not synchronized during LIA. Figure $10 \mathrm{~A}$ (middle) shows the same results as illustrated with the raw JPSTH analysis, in this case demonstrating that using LIA as a stimulus fails to contribute to synchrony. The JPSTH matrix in Figure $10 \mathrm{~A}$ (bottom) demonstrates after correcting for the stimulus (LIA) effects, the cell discharges remained nonrelated. After normalization the CIN was noisy, and the CCG display indicates that the cells were not correlated.

The analysis for the condition of LIA to theta transition is shown in Figure $10 B$. The PSTHs in Figure $10 B$ (top) indicate that both cells discharged in an irregular nonbursting pattern before and after the onset of theta. The CCG histogram indicates the cell discharges were not correlated, whereas the JPSTH matrix and CIN histogram show that the cell discharges were not synchronized throughout the same period. Figure $10 \mathrm{~B}$ (middle) shows the same results as illustrated with the raw JPSTH analysis, in this case caused by the synchronizing effects of the stimulus (theta). The JPSTH matrix in Figure $10 B$ (bottom) demonstrates after correcting for the stimulus (theta)-driven synchronizing

\section{$\leftarrow$}

cell, and the $x$-axis PST is the medial septal cell. The $x$ - and $y$-axis range was -1000 to +1000 msec. Bin width for the PSTHs and the JPSTH matrix was $9 \mathrm{msec}$, and the display for both these as well as the CCG and CIN histograms was normalized counts per trial (in hertz). The JPSTH matrix and CIN histogram in $B$ (top) show that the cells synchronized their discharges during LIA, before the onset of theta. $B$ (middle) shows the same results as illustrated with the raw JPSTH analysis, in this case caused by the synchronizing effects of the stimulus (theta). The JPSTH matrix in $B$ (bottom) demonstrates after correcting for the stimulus (theta)-driven synchronizing effects, the cell discharges were strongly related before theta onset. After normalization the CIN was noisy, but the CCG display indicates that the cells were correlated with $3.8 \%$ of the synchrony remaining. $C$, JPSTH analysis of cell pair MH5 for the condition of theta only. For all JPSTHs the $y$-axis PSTH is the hippocampal cell, and the $x$-axis PSTH is the medial septal cell. The $x$ - and $y$-axis range was -1000 to +1000 msec. Bin width for the PSTHs and the JPST matrix was 9 msec, and the display for both these as well as the CCG and CIN histograms was normalized counts per trial (in hertz). The JPSTH matrix and CIN histogram in $C$ (top) show that the cells synchronized their discharges during theta. $C$ (middle) shows the same results as illustrated with the raw JPSTH analysis, in this case because of the synchronizing effects of the stimulus (theta). The JPSTH matrix in $C$ (bottom) demonstrates after correcting for the stimulus (theta)driven synchronizing effects, the cell discharges were still strongly related. After normalization the CIN was noisy, but the CCG indicates that the cells were correlated, accounting for $4.4 \%$ of the synchrony. D, JPSTH analysis of cell pair MH5 for the condition of theta to LIA transition. For all JPSTHs the $y$-axis PSTH is the hippocampal cell, and the $x$-axis PSTH is the medial septal cell. The $x$-and $y$-axis range was -1000 to +1000 msec. Bin width for the PSTHs and the JPSTH matrix was $9 \mathrm{msec}$, and the display for both these as well as the CCG and CIN histograms was normalized counts per trial (in hertz). The JPSTH matrix and CIN histogram in $D(t o p)$ show that the cell discharges became nonsynchronized abruptly at the theta to LIA transition. $D$ (middle) shows the same results as illustrated with the raw JPSTH analysis, in this case caused by the synchronizing effects of the stimulus (theta). The JPSTH matrix in $D$ (bottom) demonstrates after correcting for the stimulus (theta)-driven synchronizing effects, the cell discharges were still strongly related during theta field activity. After normalization the CIN was noisy, but the CCG display indicates that the cells were correlated, accounting for $3.2 \%$ of the synchrony. 
A

\section{CELL PAIR MH16 - LIA ONLY}

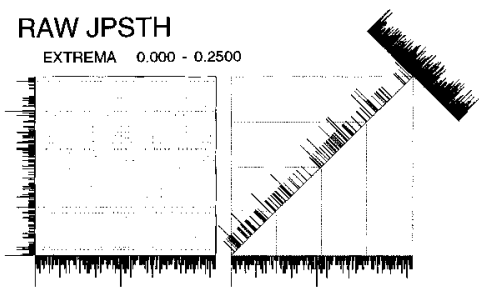

$X-M S$ CELL

$Y$-HPC CELL

CCG: $0.000-0064$

CIN: $0.000-0.0333$

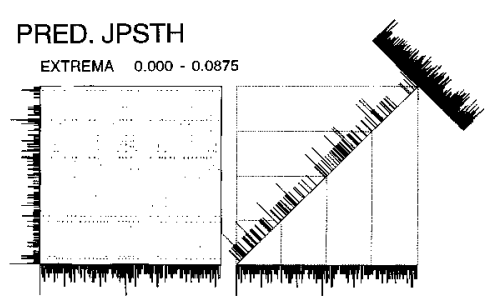

$X$-MS CELL

$\checkmark$-HPC CELL

CCG: $0.000-0.0043$

CIN: $0.000-0.0133$

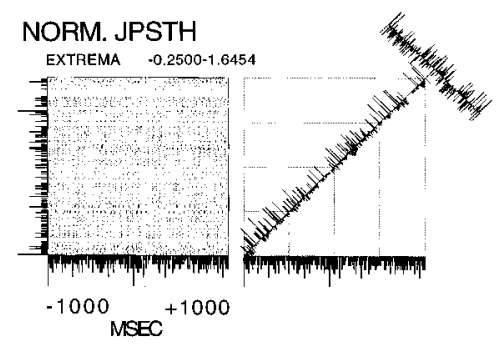

$X$-MS CELL

$Y$-HPC CELL

CCG: $-0.0182-0.0264$

CIN: $-0.0971-0.3455$
C

\section{CELL PAIR MH16 - THETA ONLY}
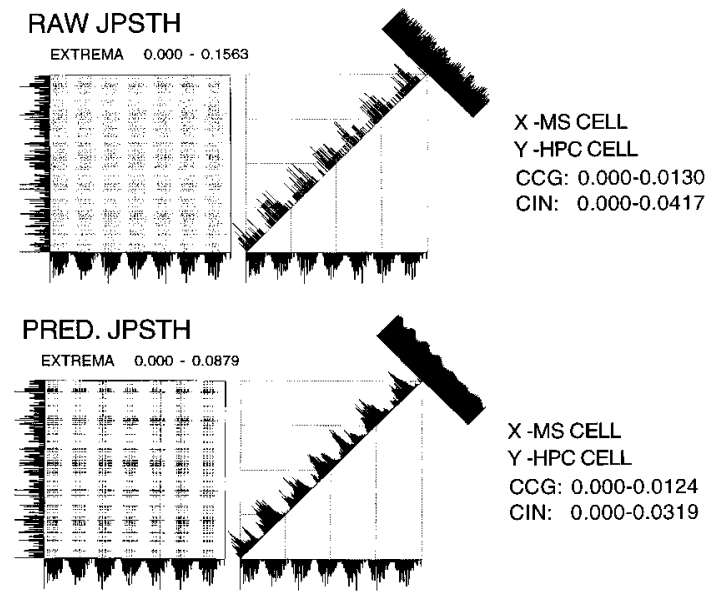

$X$-MS CELL $Y$-HPC CELL CCG: $0.000-0.0124$ CIN: $\quad 0.000-0.0319$

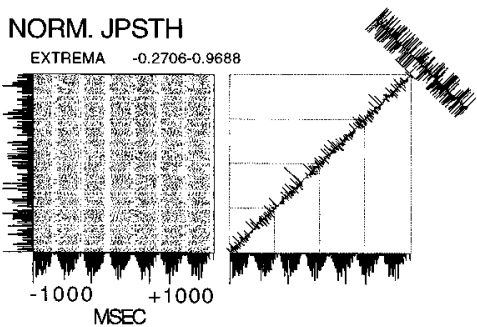

B

\section{CELL PAIR MH16 - LIA-THETA TRANSITION}
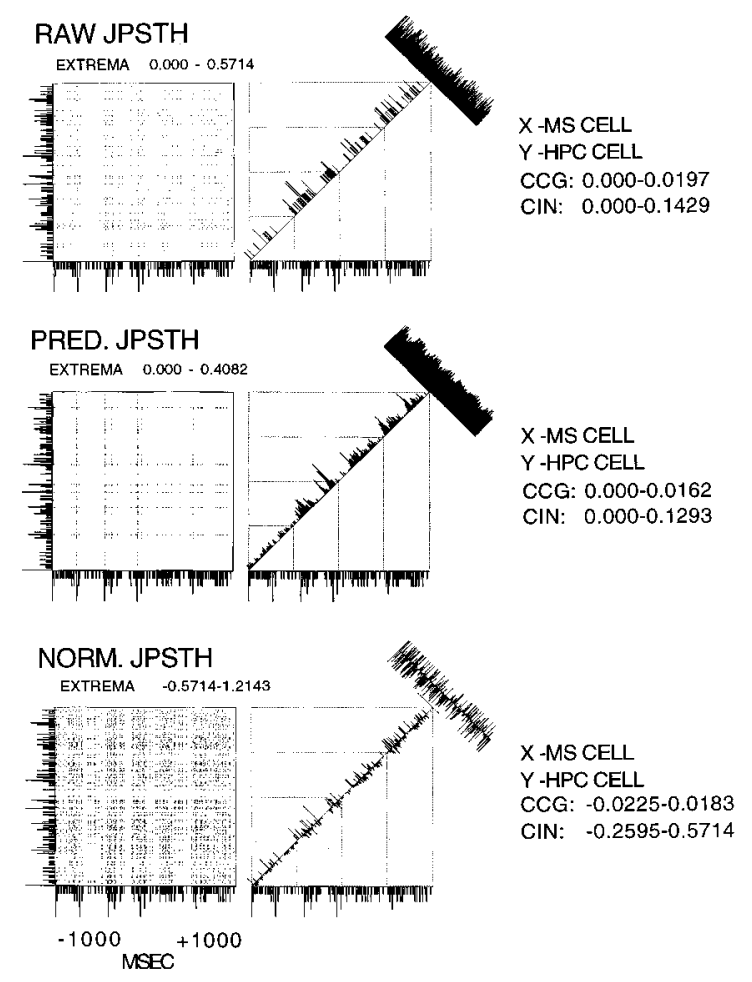

D

\section{CELL PAIR MH16 - THETA-LIA TRANSITION}
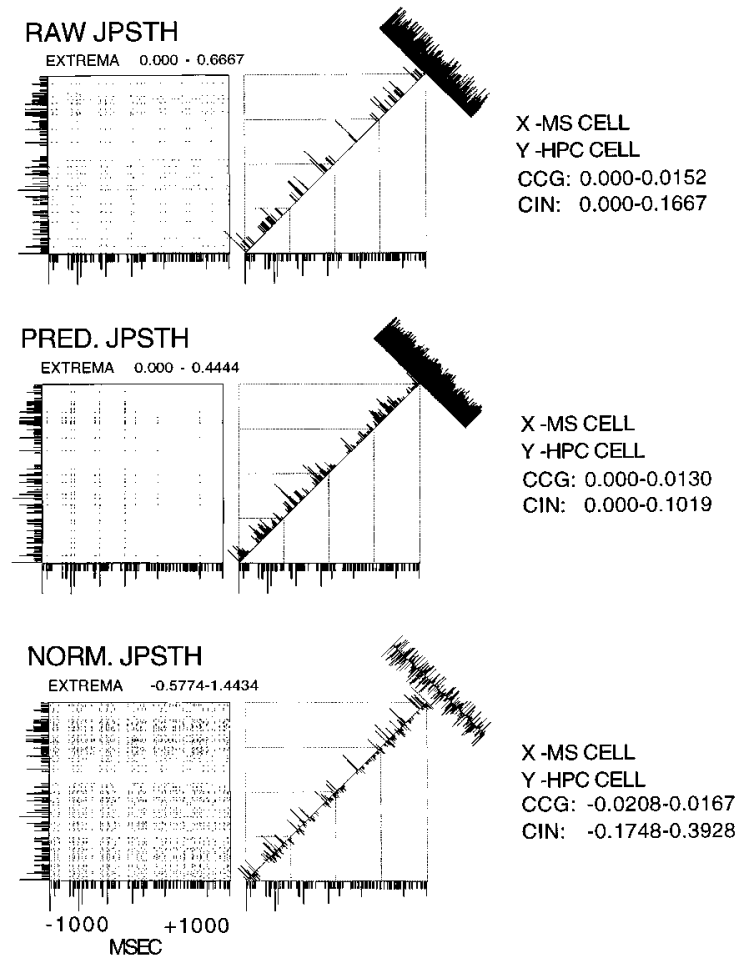

Figure 9. A, JPSTH analysis of cell pair MH16 for the condition of LIA only. For all JPSTHs the $y$-axis PSTH is the hippocampal cell, and the $x$-axis PSTH is the medial septal cell. The $x$ - and $y$ - axis range was -1000 to $+1000 \mathrm{msec}$. Bin width for the PSTHs and the JPSTH matrix was 9 msec, and the display for both these as well as the CCG and CIN histograms was normalized counts per trial (in hertz). The JPSTH matrix, and the CCG and CIN histograms for the raw (top), predicted (middle), and normalized (bottom) all indicate a lack of relationship between the cells during LIA only. B, JPSTH analysis of cell pair M16 for the condition of LIA to theta transition. For all JPSTHs the $y$-axis PSTH is the hippocampal (Figure legend continues) 
effects, the cell discharges were also not related before theta onset. After normalization the CIN was noisy, and the CCG display indicated that the cells were not correlated.

The analysis for the condition of theta only is shown in Figure $10 C$. The PSTHs in Figure $10 C$ (top) show that both cells continued to discharge in an irregular nonbursting pattern, and the CCG histogram indicates that the cell discharges were not correlated. The JPSTH matrix and CIN histogram indicate that the cells did not synchronize their discharges during theta. Figure $10 C$ (middle) shows the same results as illustrated with the raw JPSTH analysis, in this case caused by the synchronizing effects of the stimulus (theta). The JPSTH matrix in Figure 10C (bottom) demonstrates after correcting for the stimulus (theta)-driven synchronizing effects, the cell discharges were not related. After normalization the CIN was noisy, and the CCG indicates that the cells were not correlated.

The analysis for the condition of theta to LIA transition is shown in Figure 10D. The PSTHs in Figure 10D (top) indicate that during the transition from theta to LIA field activity, both cells continued discharging in an irregular nonbursting pattern, whereas the CCG histogram indicates that the cell discharges were not correlated. The JPSTH matrix and CIN histogram show that the cell discharges were not synchronized. Figure $10 \mathrm{D}$ (middle) shows the same results as illustrated with the raw JPSTH analysis, in this case caused by the synchronizing effects of the stimulus (theta). The JPSTH matrix in Figure 10D (bottom) demonstrates after correcting for the stimulus (theta)-driven synchronizing effects, the cell discharges were not related during theta field activity. After normalization the CIN was noisy, and the CCG display indicated that the cells were not correlated.

\section{Residual synchrony after the removal of theta as a "stimulus"}

Statistical analysis of the level of cross-correlation remaining between cell pairs using the normalized JPSTH analysis revealed that only medial septal phasic theta-ON/hippocampal phasic theta-ON cell pairs had any significant synchrony remaining, and only then during the LIA to theta transition and the theta only condition. Figure 11 is a graph the positive and negative Rho values of the phasic-phasic, phasic-tonic, and tonic-tonic septohippocampal cell pairs, for each of the four conditions (LIA only, LIA-theta transition, theta only, and theta-LIA transition) analyzed and plotted relative to the SDs calculated for the respective CCGs. The graph shows that only phasic-phasic cell pairs, during the transition from LIA to theta and and during the theta only condition, had significant residual synchrony, with Rho values exceeding 2 SDs from the mean $(p \leq 0.5)$.

\section{DISCUSSION}

The properties of the individual cells in the hippocampal formation and the medial septal/vertical limb of the diagonal band of Broca nuclei that were classified as theta-related in the present study corresponded to those described in our previous work in the hippocampal formation (Bland and Colom, 1988, 1989; Bland et al., 1996; Colom and Bland, 1987; Colom et al., 1987, 1991; Konopacki et al., 1992; Smythe et al., 1991), the medial septum and diagonal band of Broca (Ford et al., 1989; Bland et al., 1990, 1994; Colom and Bland, 1991), the entorhinal cortex (Dickson et al., 1994, 1995), the cingulate cortex (Colom et al., 1988), and the nuclei of the dorsomedial thalamic and posterior hypothalamic regions (Bland et al., 1995; Kirk et al., 1996).

\section{Temporal relationships between cell discharges and the transitions of spontaneously occurring field conditions}

A major finding of the present study was that changes in thetarelated septohippocampal cellular activity preceded the transition from the LIA state to the theta state by an average of $500 \mathrm{msec}$, whereas changes in theta-related cellular activity occurred nearly coincident with the transition from theta to LIA. In the hippocampal formation, the first theta-related cells to begin changing activity before the generation of theta field activity were the tonic and phasic theta-OFF cells. Specifically, tonic and phasic thetaOFF cells ceased discharging, supporting our earlier contention that these cells must be inhibited to allow theta to be generated in the hippocampus (Bland and Colom, 1993). Furthermore, the inhibition of hippocampal theta-OFF cells has been shown to be mediated by the medial septal region (Smythe et al., 1991). In the medial septum, all the phasic theta-ON cells and half the tonic theta-ON cells recorded in the present study increased their discharge rates $\sim 500 \mathrm{msec}$ before the onset of theta field activity. All these early changes in cellular discharge properties were in contrast to those occurring in hippocampal phasic and tonic theta-ON cells, both of which changed activity coincident with the onset of hippocampal theta field activity. In marked contrast to the cellular changes that did occur in the time period preceding the transition from LIA to theta field activity, none of the thetarelated cells in the present study (medial septal or hippocampal)

\footnotetext{
cell, and the $x$-axis PSTH is the medial septal cell. The $x$ - and $y$-axis range was -1000 to +1000 msec. Bin width for the PSTHs and the JPSTH matrix was $9 \mathrm{msec}$, and the display for both these as well as the CCG and CIN histograms was normalized counts per trial (in hertz). The JPSTH matrix and CIN histogram in $B$ (top) show that the cells synchronized their discharges during LIA, before the onset of theta. $B$ (middle) shows the same results as illustrated with the raw JPSTH analysis, in this case caused by the synchronizing effects of the stimulus (theta). The JPSTH matrix in $B$ (bottom) demonstrates after correcting for the stimulus (theta)-driven synchronizing effects, the cell discharges were related before theta onset. After normalization the CIN was noisy, but the CCG display indicates that the cells were weakly correlated, accounting for $1.8 \%$ of the synchrony. $C$, JPSTH analysis of cell pair MH16 for the condition of theta only. For all JPSTHs the $y$-axis PSTH is the hippocampal cell, and the $x$-axis PSTH is the medial septal cell. The $x$ - and $y$-axis range was -1000 to $+1000 \mathrm{msec}$. Bin width for the PSTHs and the JPSTH matrix was 9 msec, and the display for both these as well as the CCG and CIN histograms was normalized counts per trial (in hertz). The JPSTH matrix and CIN histogram in $C$ (top) indicate that the cells synchronized their discharges during theta. $C$ (middle) shows the same results as illustrated with the raw JPSTH analysis, in this case caused by the synchronizing effects of the stimulus (theta). The JPSTH matrix in $C$ (bottom) demonstrates after correcting for the stimulus (theta)-driven synchronizing effects, the cell discharges were still related. After normalization the CIN was noisy, but the CCG indicates that the cells were weakly correlated, accounting for $1.5 \%$ of the synchrony. $D$, JPSTH analysis of cell pair MH16 for the condition of theta to LIA transition. For all JPSTHs the $y$-axis PSTH is the hippocampal cell, and the $x$-axis PSTH is the medial septal cell. The $x$ - and $y$-axis range was -1000 to $+1000 \mathrm{msec}$. Bin width for the PSTHs and the JPSTH matrix was $9 \mathrm{msec}$, and the display for both these as well as the CCG and CIN histograms was normalized counts per trial (in hertz). The JPSTH matrix and CIN histogram in $D$ (top) show that the cell discharges became nonsynchronized abruptly at the theta to LIA transition. $D$ (middle) shows the same results as illustrated with the raw JPSTH analysis, in this case caused by the synchronizing effects of the stimulus (theta). The JPSTH matrix in $D$ (bottom) demonstrates after correcting for the stimulus (theta)-driven synchronizing effects, the cell discharges were not related during theta field activity. After normalization the CIN was noisy, and the CCG display indicates that the cells were not correlated.
} 
A

\section{CELL PAIR MH8- LIA ONLY}
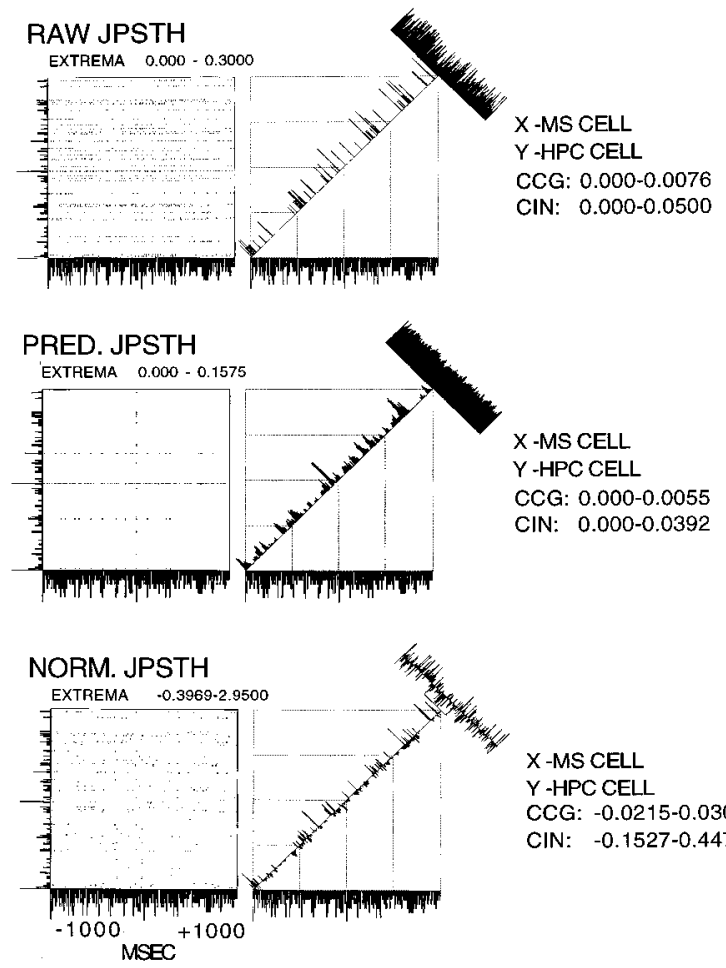

$X-M S$ CELL

$Y$-HPC CELL

CCG: $-0.0215-0.0307$

CIN: $-0.1527-0.4478$

\section{C}
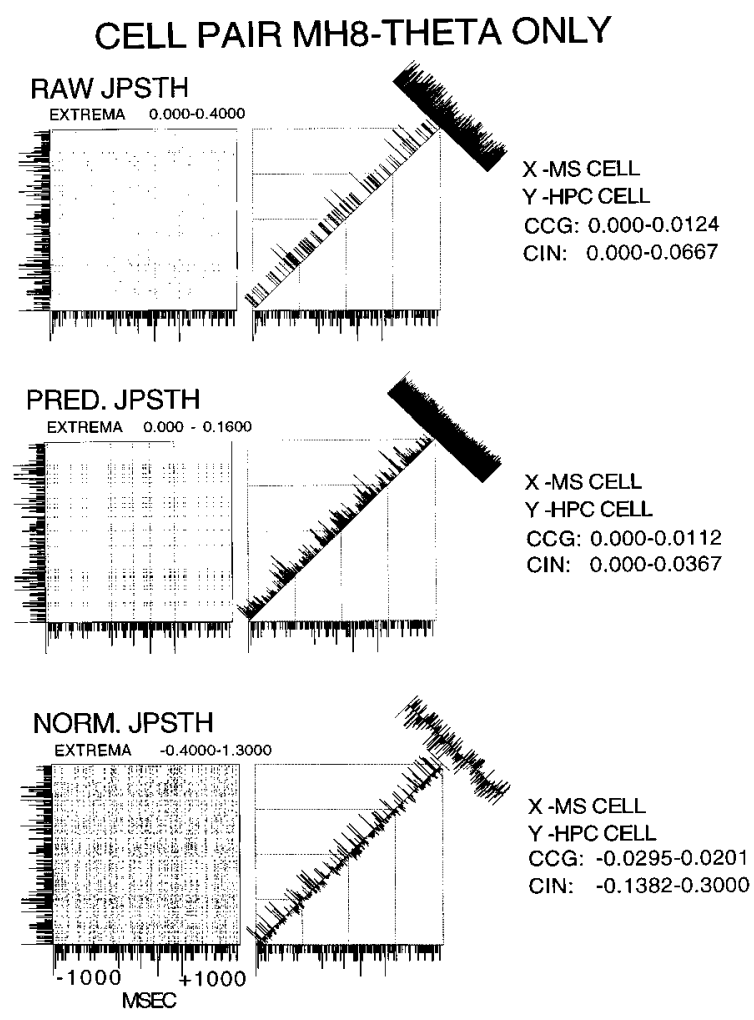

B

CELL PAIR MH8-LIA-THETA TRANSITION
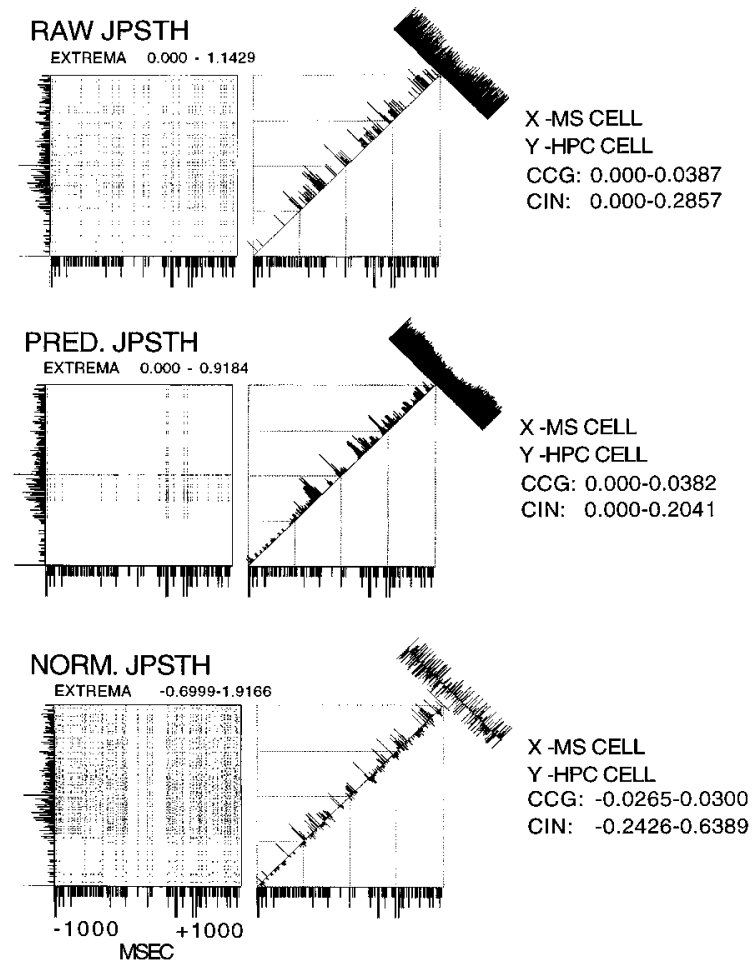

D

\section{CELL PAIR MH8-THETA-LIA TRANSITION}
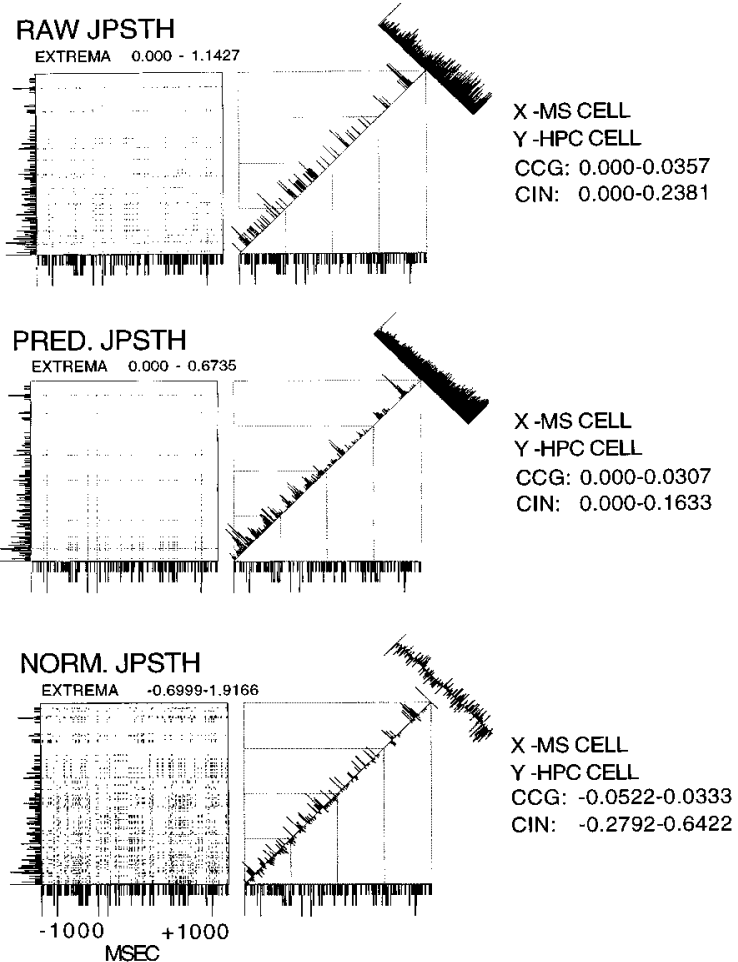

Figure 10. A, JPSTH analysis of cell pair MH8 for the condition of LIA only. For all JPSTs, the $y$-axis PSTH is the hippocampal cell, and the $x$-axis PSTH is the medial septal cell. The $x$ - and $y$-axis range was -1000 to $+1000 \mathrm{msec}$. Bin width for the PSTHs and the JPSTH matrix was 9 msec, and the display for both these as well as the CCG and CIN histograms was normalized counts per trial (in hertz). The JPSTH matrix, and the CCG and CIN histograms for the raw (top), predicted (middle), and normalized (bottom) all indicate a lack of relationship between the cells during LIA only. B, JPSTH analysis of cell pair MH8 for the condition of LIA to theta transition. For all JPSTHs the $y$-axis PSTH is the hippocampal (Figure legend continues) 
changed their activity in the time period preceding the transition from theta to LIA field activity.

\section{Time-averaged cross-correlational analyses (cells vs fields and cells vs cells)}

Cross-correlation analyses performed for the LIA only condition revealed there were no correlations between any of the individual theta-related cell discharges and LIA field activity or between the discharges of any of the cell pairs. Cross-correlational analyses performed for the theta only condition revealed that all individual medial septal phasic theta-ON cell and hippocampal phasic theta-ON cell discharges were strongly correlated with theta field activity (supporting many previous observations) (for review, see Bland, 1986) and were correlated with each other. The latter finding supports the results of Alonso et al. (1987).

Medial septal tonic theta-ON and hippocampal tonic theta-ON cells in the present study all showed weak to moderate correlations with theta field activity, indicating that although their discharges were nonrhythmic there was a tendency for them to discharge preferentially during a particular cycle of the theta. This observation made for medial septal tonic theta-ON cells and hippocampal tonic theta-ON cells supports the earlier findings for type 2 cells reported by Garcia-Austt et al. (1977), GarciaSanchez et al. (1978), Fuentes et al. (1981), Gaztelu et al. (1982), and Alonso et al. (1987). In agreement with these authors, we conclude that the findings provide evidence that tonic theta-ON cells (their type 2 cells) are involved in the control of oscillation and synchrony in the hippocampal formation. More specifically, we believe that medial septal tonic theta-ON cells provide tonic depolarizing inputs to hippocampal phasic theta-ON cells to initiate MPOs (Bland and Colom, 1993). The finding of a moderate cross-correlation between two pairs of medial septal tonic theta-ON/hippocampal tonic theta-ON cells in the present study during the theta only condition was in agreement with results reported by Alonso et al. (1987). Medial septal phasic theta-ON cells and hippocampal tonic theta-ON cells were all moderately cross-correlated during the theta only condition, a result that was also reported by Alonso et al. (1987). Unlike the phase relationship described above for phasic-phasic theta-ON cell pairs, the phase relationship between the phasic-tonic theta-ON pairs was closer to that between the medial septal cell and the theta field. A possible explanation for this finding is that hippocampal tonic theta-ON cells do not have intrinsic MPOs (Konopacki et al., 1992).

\section{Time-dependent (JPSTH) analyses of septohippocampal cell pairs}

One of the most significant results of the present work was the finding that the discharges of medial septal phasic theta-ON cell/hippocampal phasic theta-ON cell and medial septal phasic theta-ON cell/hippocampal tonic theta-ON cell pairs became strongly synchronized an average of $500 \mathrm{msec}$ before the onset of theta field activity. The predicted JPSTH analyses, although showing the same result for both these cell pair combinations, further indicated that theta was the major factor in producing the neural synchrony. However, the normalized JPSTH analyses revealed that when the "stimulus" of theta was removed, significant synchrony remained in the case of phasic-phasic theta-ON septohippocampal cell pairs (a mean of 4\%), but not in the case of phasic-tonic theta-ON cell pairs. Based on our previous findings that only phasic HPC theta cells have intrinsic MPOs and only during the simultaneous occurrence of theta field activity, not LIA (Bland et al., 1988; Konopacki et al., 1992), along with reports that rhythmically bursting medial septal cells display prominent MPOs (Barrenechea et al., 1995; Serafin et al., 1996; Brazhnik and Fox, 1997), the present data supported the conclusion that the remaining neural synchrony observed between phasic-phasic septohippocampal theta-ON cell pairs was caused by the progressive synchronization of their MPOs. That is, activity in the ascending brainstem synchronizing pathways progressively recruits medial septal phasic theta-ON cells (Colom and Bland, 1991) to initiate MPOs and these in turn progressively recruit hippocampal phasic theta-ON cell MPOs.

The discharges of medial septal phasic theta-ON cell/hippocampal phasic theta-ON cell and medial septal phasic theta-ON cell/hippocampal tonic theta-ON cell pairs continued to remain strongly synchronized during the theta only condition, as revealed by the raw JPSTH analyses. The predicted JPSTH analyses indicated that theta was the major factor in producing the neural synchrony. Once again, in the case of phasic-phasic theta-ON cell pairs, the normalized JPSTHs analyses showed that when the effect of theta was removed, significant synchrony remained. In the case of medial septal phasic theta-ON cell/hippocampal tonic theta-ON cell combinations, no significant synchrony remained after the effects of theta were removed. Again, this may be caused by the fact that hippocampal tonic theta-ON cells do not have MPOs during theta field activity.

The raw and predicted JPSTH analyses for the theta to LIA

\section{$\leftarrow$}

cell, and the $x$-axis PSTH is the medial septal cell. The $x$ - and $y$-axis range was -1000 to +1000 msec. Bin width for the PSTHs and the JPSTH matrix was $9 \mathrm{msec}$, and the display for both these as well as the CCG and CIN histograms was normalized counts per trial (in hertz). The JPSTH matrix and CIN histogram in $B$ (top) show that the cell discharges were not synchronized. $B$ (middle) shows the same results as illustrated with the raw JPSTH analysis, in this case caused by the synchronizing effects of the stimulus (theta). The JPSTH matrix in $B$ (bottom) demonstrates after correcting for the stimulus (theta)-driven synchronizing effects, the cell discharges were also not related previous to theta onset. After normalization the CIN was noisy, and the CCG display indicated that the cells were not correlated. C, JPSTH analysis of cell pair MH8 for the condition of theta only. For all JPSTHs the $y$-axis PSTH is the hippocampal cell, and the $x$-axis PSTH is the medial septal cell. The $x$-and $y$-axis range was -1000 to +1000 msec. Bin width for the PSTHs and the JPSTH matrix was $9 \mathrm{msec}$, and the display for both these as well as the CCG and CIN histograms was normalized counts per trial (in hertz). The JPSTH matrix and CIN histogram in $C$ (top) indicate that the cells did not synchronize their discharges during theta. $C$ (middle) shows the same results as illustrated with the raw JPSTH analysis, in this case caused by the synchronizing effects of the stimulus (theta). The JPSTH matrix in $C$ (bottom) demonstrates after correcting for the stimulus (theta)-driven synchronizing effects, the cell discharges were not related. After normalization the CIN was noisy, and the CCG indicates that the cells were not correlated. $D$, JPSTH analysis of cell pair MH8 for the condition of theta to LIA transition. For all JPSTHs the $y$-axis PSTH is the hippocampal cell, and the $x$-axis PSTH is the medial septal cell. The $x$-and $y$-axis range was -1000 to $+1000 \mathrm{msec}$. Bin width for the PSTHs and the JPSTH matrix was $9 \mathrm{msec}$, and the display for both these as well as the CCG and CIN histograms was normalized counts per trial (in hertz). The JPSTH matrix and CIN histogram in $D$ (top) show that the cell discharges were not synchronized. $D$ (middle) shows the same results as illustrated with the raw JPSTH analysis, in this case caused by the synchronizing effects of the stimulus (theta). The JPSTH matrix in $D$ (bottom) demonstrates after correcting for the stimulus (theta)-driven synchronizing effects, the cell discharges were not related during theta field activity. After normalization the CIN was noisy, and the CCG display indicated that the cells were not correlated. 


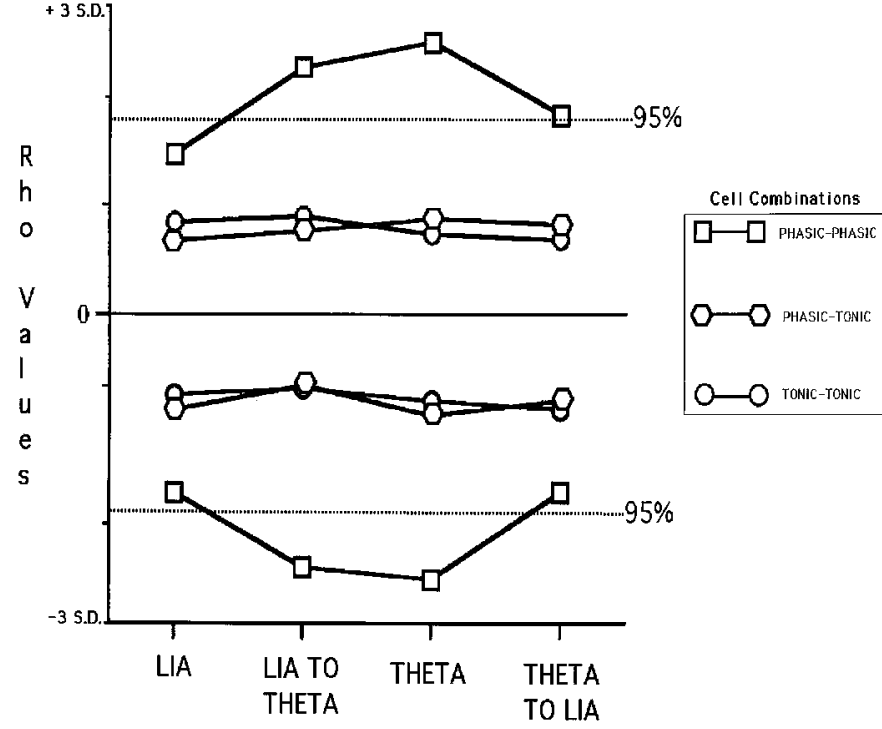

Figure 11. Graph of the positive and negative Rho values of the phasicphasic, phasic-tonic, and tonic-tonic septohippocampal cell pairs, for each of the four conditions analyzed (LIA, LIA TO THETA, THETA, and THETA TO LIA), plotted relative to the SDs calculated for the respective CCGs. Only phasic-phasic cell pairs during the LIA to theta transition and the theta only condition had significant values $(>2$ SDs from the mean) $(p \leq 0.05)$.

transition revealed that phasic-phasic and phasic-tonic theta-ON cell pairs became nonsynchronized abruptly at the termination of theta field activity, and the normalized JPSTH analyses indicated that when the effects of theta were removed the remaining synchrony was not significant. Taken together, the results of the JPSTH analyses of the theta to LIA transitions strongly suggested that the termination of hippocampal phasic theta-ON cell activity (and therefore hippocampal theta field activity) occurs through a rapid and strong inhibition by hippocampal theta-OFF cells, which in turn is a result of the disinhibition of the latter by the GABAergic septohippocampal pathway (Smythe et al., 1991).

In summary, the present study demonstrated that the transition from the LIA state to the theta field state in the hippocampal formation requires a temporal sequence of changes in thetarelated cellular activity occurring on average $500 \mathrm{msec}$ preceding the transition: (1) the medial septum inhibits hippocampal thetaOFF cells; and (2) medial septal tonic theta-ON cells provide tonic depolarizing inputs to initiate MPOs in hippocampal phasic theta-ON cells, whereas medial septal phasic theta-ON cells synchronize the MPOs of hippocampal phasic theta-ON cells and the discharges of hippocampal tonic theta-ON cells. Much of the time preceding the LIA to theta transition is accounted for by recruitment of these theta-related cell populations, first in the medial septum and then in the hippocampal formation. Conversely, "turning off" the theta state occurs abruptly and involves the medial septal disinhibition of hippocampal theta-OFF cells.

\section{REFERENCES}

Ahmed N, Rao KR (1975) Orthogonal transforms for digital signal processing. Berlin: Springer.

Alonso A, Gaztelu JM, Buno Jr W, Garcia-Austt E (1987) Crosscorrelation analysis of septohippocampal neurons during $\theta$-rhythm. Brain Res 413:135-146.

Artemenko DP (1973) Participation of hippocampal neurons in thetawave generation. Neurophysiology 4:409-415.

Barrenechea C, Pedemonte M, Nunez A, Garcia-Austt E (1995) In vivo intracellular recordings of medial septal and diagonal band of Broca neurons: relationships with theta rhythm. Exp Brain Res 103:31-40.

Bland BH (1986) The physiology and pharmacology of hippocampal formation theta rhythms. Prog Neurobiol 26:1-54.

Bland BH, Colom LV (1988) Responses of phasic and tonic hippocampal theta-on cells to cholinergics: differential effects of muscarinic and nicotinic activation. Brain Res 440:167-171.

Bland BH, Colom LV (1989) Preliminary observations on the physiology and pharmacology of hippocampal theta-off cells. Brain Res 505:333-336.

Bland BH, Colom LVC (1993) Extrinsic and intrinsic properties underlying oscillation and synchrony in limbic cortex. Prog Neurobiol 41:157-208.

Bland BH, Oddie SD (1998) Anatomical, electrophysiological and pharmacological studies of ascending brainstem hippocampal synchronizing pathways. Neurosci Biobehav Rev 22:259-273.

Bland BH, Colom LV, Konopacki J, Roth SH (1988) Intracellular records of carbachol-induced theta rhythm in hippocampal slices. Brain Res 447:364-368.

Bland BH, Colom LV, Ford RD (1990) Responses of septal theta-on and theta-off cells to activation of the dorsomedial-posterior hypothalamic region. Brain Res Bull 24:71-79.

Bland BH, Oddie SD, Colom LV, Vertes RP (1994) Extrinsic modulation of medial septal cell discharges by the ascending brainstem hippocampal synchronizing pathway. Hippocampus 6:649-660.

Bland BH, Konopacki J, Kirk IJ, Oddie SD, Dickson CT (1995) Discharge patterns of hippocampal theta-related cells in the caudal diencephalon of the urethan-anesthetized rat. J Neurophysiol 74:322-333.

Bland BH, Trepel C, Oddie SD, Kirk IJ (1996) Intraseptal microinf usion of muscimol: effects on hippocampal formation field activity and phasic theta-on cell discharges. Exp Neurol 138:286-297.

Bland BH, Colom LV, Oddie SD, Kirk IJ, Scarlett D (1997) Mechanisms of hippocampal theta generation: evidence from simultaneous recordings of medial septal and hippocampal cells. Soc Neurosci Abstr 23:486.

Brazhnik ES, Fox SE (1997) Intracellular recordings from medial septal neurons during hippocampal theta rhythm. Exp Brain Res 114:442-453

Buzsaki G (1989) Two-stage model of memory trace formation: a role for "noisy" brain states. Neuroscience 31:551-570.

Colom LV, Bland BH (1987) State-dependent spike train dynamics of hippocampal formation neurons: evidence for theta-on and theta-off cells. Brain Res 422:277-286.

Colom LV, Bland BH (1991) Medial septal cell interactions in relation to hippocampal field activity and the effects of atropine. Hippocampus $1: 15-30$.

Colom LV, Ford RD, Bland BH (1987) Hippocampal formation neurons code the level of activation of the cholinergic septo-hippocampal pathway. Brain Res 410:12-20.

Colom LV, Christie BR, Bland BH (1988) Cingulate cell discharge patterns related to hippocampal EEG and their modulation by muscarinic and nicotinic agents. Brain Res 460:329-338.

Colom LV, Nassif-Caudarella S, Dickson CT, Smythe JW, Bland BH (1991) In vivo intrahippocampal microinfusion of carbachol and bicuculline induces theta-like oscillations in the septally deafferented hippocampus. Hippocampus 1:381-390.

Dickson CT, Trepel C, Bland BH (1994) Extrinsic modulation of theta field activity in the entorhinal cortex of the anesthetized rat. Hippocampus 4:37-52.

Dickson CT, Kirk IJ, Oddie SD, Bland BH (1995) Classification of theta-related cells in the entorhinal cortex: cell discharges are controlled by the ascending brainstem synchronizing pathway in parallel with hippocampal theta-related cells. Hippocampus 5:306-319.

Dutar P, Bassant M-H, Senut M-C, Lamour Y (1995) The septohippocampal pathway: structure and function of a central cholinergic system. Physiol Rev 75:393-427.

Ford RD, Colom LV, Bland BH (1989) The classification of medial septum-diagonal band cells as theta-on or theta-off in relation to hippocampal EEG states. Brain Res 493:269-282.

Fox SE (1989) Membrane potential and impedance changes in hippocampal pyramidal cells during theta rhythm. Exp Brain Res 77:283-294

Fuentes J, Buno Jr W, Garcia-Austt E (1981) Simulation of post-synaptic activities in hippocampal cells during theta rhythm. Brain Res Bull 7:157-162. 
Fujita Y, Sato T (1964) Intracellular records from hippocampal pyramidal cells in rabbits during theta rhythm activity. J Neurophysiol 27:1011-1025.

Garcia-Austt E, Buno Jr W, Garcia-Sanchez JL (1977) Analysis of unit pairs in the hippocampus. Acta Neurol Latinoam 23:141-153.

Garcia-Sanchez JL, Buno Jr W, Fuentes J, Garcia-Austt E (1978) Nonrhythmical hippocampal units, theta rhythm and afferent stimulation. Brain Res Bull 3:213-219.

Gatztelu JM, Buno Jr W (1982) Septo-hippocampal relationships during EEG theta rhythm. Electroencephalogr Clin Neurophysiol 54:375-387.

Gerstein GL (1970) Functional associations of neurons: detection and interpretation. In: The neurosciences: second study program (Schmitt FO, ed), pp 648-661. New York: Rockefeller UP.

Huerta PT, Lisman JE (1993) Heightened synaptic plasticity of hippocampal CA1 neurons during cholinergically induced rhythmic state. Nature 364:723-725.

Kirk IJ, Oddie SD, Konopacki J, Bland BH (1996) Evidence for differential control of posterior hypothalamic, supramammillary, and medial mammillary theta-related cellular discharge by ascending and descending pathways. J Neurosci 16:5547-5554.

Konopacki J, Bland BH, Colom LV, Oddie SD (1992) In vivo intracellular correlates of hippocampal formation theta-on and theta-off cells. Brain Res 586:247-255.

Leung L-W-S, Yim C-YC (1986) Intracellular records of theta rhythm in hippocampal CA1 cells of the rat. Brain Res 367:323-327.

Leung L-W-S, Yim C-Y-C (1988) Membrane potential oscillations in hippocampal neurons in vitro induced by carbachol or depolarizing currents. Neurosci Res Commun 2:159-167.

Leung L-W-S, Yim C-YC (1991) Intrinsic membrane potential oscillations in hippocampal neurons in vitro. Brain Res 553:261-274.

Leung L-W-S, Lopes Da Silva FH, Wadman WJ (1982) Spectral characteristics of the hippocampal EEG in the freely moving rat. Electroencephalogr Clin Neurophysiol 54:203-219.

Macadar O, Roig JA, Monti JM, Budelli R (1970) The functional relationship between septal and hippocampal unit activity and hippocampal theta rhythm. Physiol Behav 5:1443-1449.

MacVicar BA, Tse FWY (1989) Local neuronal circuitry underlying cholinergic rhythmical slow activity in CA3 area of rat hippocampal slices. J Physiol (Lond) 417:197-212.

Miller R (1991) Cortico-hippocampal interplay and the representation of contexts in the brain. Berlin: Springer.

Munoz MD, Nunez A, Garcia-Austt E (1990) In vivo intracellular analysis of rat dentate granule cells. Brain Res 509:91-98.

Nunez A, Garcia-Austt E, Buno Jr W (1987) Intracellular theta rhythm generation in identified hippocampal pyramids. Brain Res 416:289-300.

Nunez A, Garcia-Austt E, Buno Jr W (1990a) Synaptic contributions to theta rhythm genesis in rat CA1-CA3 hippocampal pyramidal neurons in vivo. Brain Res 533:176-179.
Nunez A, Garcia-Austt E, Buno Jr W (1990b) Slow intrinsic spikes recorded in vivo in rat CA1- CA3 hippocampal pyramidal neurons. Exp Neurol 109:294-299.

Nunez A, Garcia Austt E, Buno Jr W (1990c) In vivo electrophysiological analysis of Lucifer yellow-coupled hippocampal pyramids. Exp Neurol 108:76-82.

Oddie SD, Bland BH (1998) Hippocampal formation theta activity and movement selection. Neurosci Biobehav Rev 22:221-231.

O'Keefe J, Recce ML (1993) Phase relationship between hippocampal place units and the EEG theta rhythm. Hippocampus 3:317-330.

Pavlides C, Greenstein YJ, Grudman M, Winson J (1988) Long-term potentiation in the dentate gyrus is preferentially on the positive phase of theta rhythm. Brain Res 439:383-387.

Perkel DH, Gerstein GL, Moore GP (1967) Neuronal spike trains and stochastic processes. II. Simultaneous spike trains. Biophys J 7:419-440.

Press WH, Flanner BB, Teukolsky SA, Vetterling WT (1986) Numerical recipes: the art of scientific computing. Cambridge: Cambridge UP.

Richmond BJ, Optican LM, Podell M, Spitzer H (1987) Temporal encoding of two-dimensional patterns by single units in primate inferior temporal cortex. I. Response characteristics. J Neurophysiol $57: 132-146$.

Saul LJ, Davis H (1933) Action currents in the central nervous system. Arch Neurol Psychiat Chicago 29:255-259.

Serafin M, Williams S, Khateb A, Fort P, Muhlethaler M (1996) Rhythmic firing of medial septum non-cholinergic neurons. Neuroscience 75:671-675.

Skaggs WE, MacNaughton BL (1996) Replay of neuronal firing sequences in rat hippocampus during sleep following spatial experience. Science 271:1870-1873.

Smythe JW, Christie BR, Colom LV, Lawson VH, Bland BH (1991) Hippocampal theta field activity and theta-on/theta-off cell discharges are controlled by an ascending hypothalamo-septal pathway. J Neurosci 11:2241-2248.

Swanson LW (1992) Brain maps: structure of the rat brain. Amsterdam: Elsevier.

Tse FWY, MacVicar BA (1989) Phosphoinositides and GTP binding proteins involved in muscarinic generation of hippocampal rhythmic slow activity. Neurosci Lett 102:58-63.

Vertes RP, Kocsis B (1997) Brainstem-diencephalo-septohippocampal systems controlling the theta rhythm of the hippocampus. Neuroscience 81:893-926.

Vinogradova OS (1995) Expression, control, and probable functional significance of the neuronal theta-rhythm. Prog Neurobiol 45:532-583.

Yim C-YC, Leung L-W-S (1988) Effects of carbachol perfusion on evoked responses and excitability of pyramidal cells in the hippocampal slice. Neurosci Res Commun 2:47-52. 